\title{
Impact of the spatial distribution of the atmospheric forcing on water mass formation in the Mediterranean Sea
}

\author{
Karine Béranger, ${ }^{1}$ Yann Drillet, ${ }^{2}$ Marie-Noëlle Houssais, ${ }^{3}$ Pierre Testor, ${ }^{3}$ \\ Romain Bourdallé-Badie, ${ }^{4}$ Bahjat Alhammoud, ${ }^{3}$ Alexandra Bozec,${ }^{3}$ Laurent Mortier, ${ }^{1,3}$ \\ Pascale Bouruet-Aubertot, ${ }^{3}$ and Michel Crépon ${ }^{3}$ \\ Received 16 July 2009; revised 10 August 2010; accepted 19 August 2010; published 17 December 2010.
}

[1] The impact of the atmospheric forcing on the winter ocean convection in the Mediterranean Sea was studied with a high-resolution ocean general circulation model. The major areas of focus are the Levantine basin, the Aegean-Cretan Sea, the Adriatic Sea, and the Gulf of Lion. Two companion simulations differing by the horizontal resolution of the atmospheric forcing were compared. The first simulation (MED16-ERA40) was forced by air-sea fields from ERA40, which is the ECMWF reanalysis. The second simulation (MED16-ECMWF) was forced by the ECMWF-analyzed surface fields that have a horizontal resolution twice as high as those of ERA40. The analysis of the standard deviations of the atmospheric fields shows that increasing the resolution of the atmospheric forcing leads in all regions to a better channeling of the winds by mountains and to the generation of atmospheric mesoscale patterns. Comparing the companion ocean simulation results with available observations in the Adriatic Sea and in the Gulf of Lion shows that MED16-ECMWF is more realistic than MED16-ERA40. In the eastern Mediterranean, although deep water formation occurs in the two experiments, the depth reached by the convection is deeper in MED16-ECMWF. In the Gulf of Lion, deep water formation occurs only in MED16-ECMWF. This larger sensitivity of the western Mediterranean convection to the forcing resolution is investigated by running a set of sensitivity experiments to analyze the impact of different time-space resolutions of the forcing on the intense winter convection event in winter 1998-1999. The sensitivity to the forcing appears to be mainly related to the effect of wind channeling by the land orography, which can only be reproduced in atmospheric models of sufficient resolution. Thus, well-positioned patterns of enhanced wind stress and ocean surface heat loss are able to maintain a vigorous gyre circulation favoring efficient preconditioning of the area at the beginning of winter and to drive realistic buoyancy loss and mixing responsible for strong convection at the end of winter.

Citation: Béranger, K., Y. Drillet, M.-N. Houssais, P. Testor, R. Bourdallé-Badie, B. Alhammoud, A. Bozec, L. Mortier, P. Bouruet-Aubertot, and M. Crépon (2010), Impact of the spatial distribution of the atmospheric forcing on water mass formation in the Mediterranean Sea, J. Geophys. Res., 115, C12041, doi:10.1029/2009JC005648.

\section{Introduction}

[2] The Mediterranean Sea (Figure 1a) is a concentration basin in which, on an annual basis, evaporation exceeds the fresh water supply due to precipitation and river runoff. Concomitantly, air-sea heat fluxes lead to a net loss for the ocean. The salinification and cooling that result from these

\footnotetext{
${ }^{1}$ Department of Mechanical Engineering, ENSTA-ParisTech, Palaiseau, France.

${ }^{2}$ Mercator Ocean, Ramonville-Saint-Agne, France.

${ }^{3}$ LOCEAN, Université Pierre and Marie Curie, Paris, France.

${ }^{4}$ CERFACS, Toulouse, France.
}

Copyright 2010 by the American Geophysical Union. 0148-0227/10/2009JC005648 surface exchanges must be compensated by horizontal exchanges through the Strait of Gibraltar. The compensation occurs through a surface inflow of fresh and warm Atlantic Water (AW) and deep outflow of relatively salty and cold Mediterranean water (Figure 1b). The Mediterranean Sea acts as a thermodynamic engine driven by the air-sea exchanges, which transforms the light inflowing AW into the denser, deeper Mediterranean Outflow Water. An overall picture of the distribution of the convection is often obtained from estimates of the winter mixed layer depth based on hydrographic observations. The synthetic description of the seasonal mixed layer for the whole Mediterranean Sea given by D'Ortenzio et al. [2005] gives useful insight into the spatial contrasts of the winter convection in the Mediterranean Sea. Direct observations of convection are more difficult. A common feature of the 
(a)

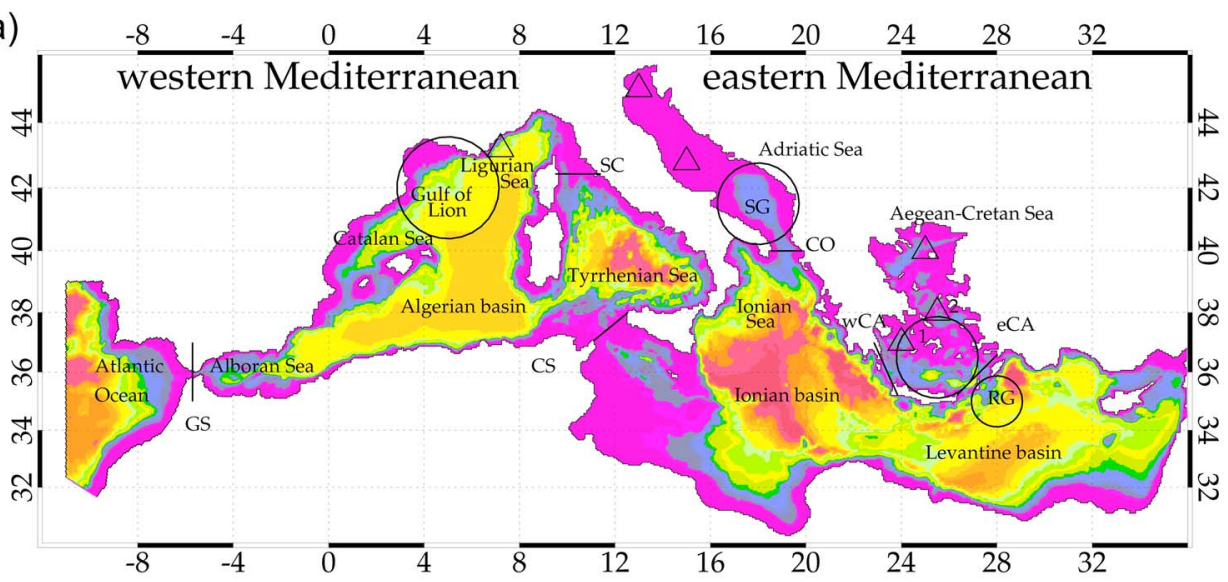

$0 \quad 200 \quad 400 \quad 600 \quad 800 \quad 1000 \quad 1200 \quad 1400 \quad 1600 \quad 1800 \quad 2000 \quad 2200 \quad 2400 \quad 2600 \quad 2800 \quad 3000 \quad 320034003600 \quad 3800 \quad 4000$

(b)

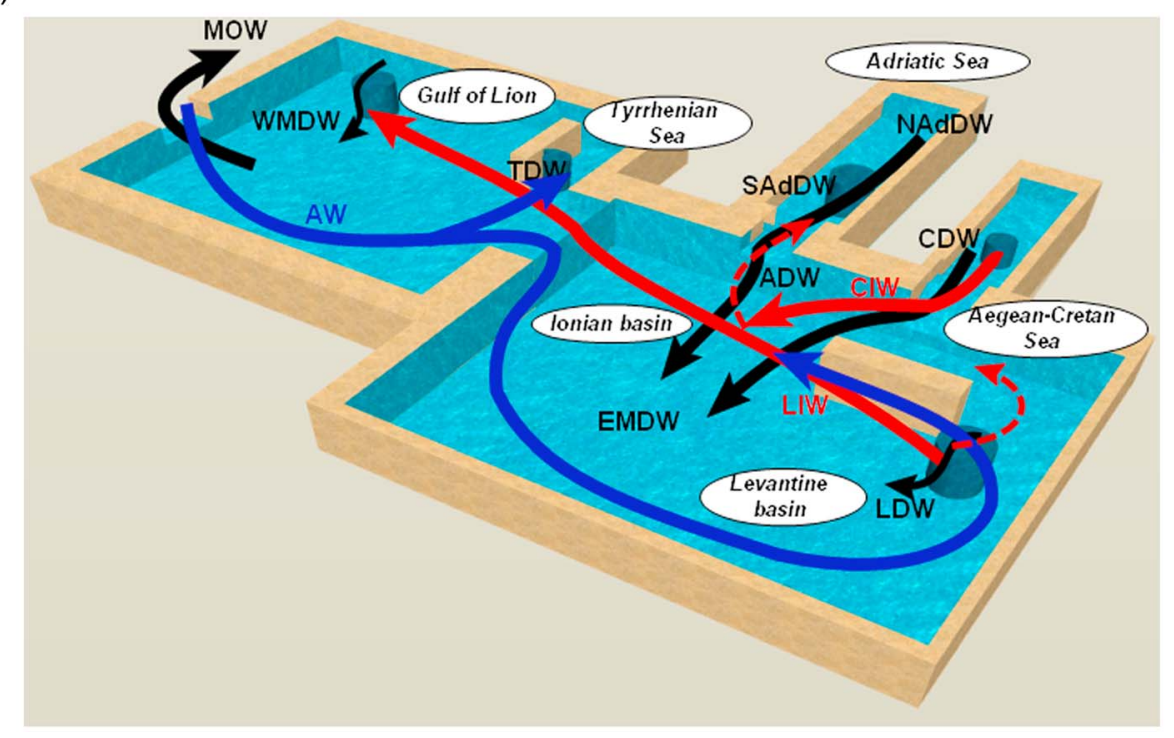

Figure 1. (a) Bathymetry of the MED16 model of the Mediterranean Sea. Black lines indicate the Strait of Gibraltar (GS), the Strait of Corsica (SC), the Channel of Sicily (CS), the Channel of Otranto (CO), the western straits of the Cretan Arc (wCA) and the eastern straits of the Cretan Arc (eCA). Major sites of deep water formation are circled [Millot, 1999], in particular the Sad Gyre (SG) and the Rhodes Gyre (RG) areas, and triangles indicate other sites of winter convection in the Ligurian Sea [Smith et al., 2008], in the Tyrrhenian Sea [Fuda et al., 2002], in the Adriatic Sea [Artegiani et al., 1997] and in the north Aegean-Cretan Sea [Nittis et al., 2003]. In the Aegean-Cretan Sea, the Cyclades plateau (1) and the Skyros and Chios areas (2) are indicated. (b) Schematic of the areas of deep water formation and pathways in the Mediterranean Sea. The surface circulation of Atlantic Water (AW) is in blue; the intermediate water circulation is in red and involves the Levantine Intermediate Water (LIW) and the Cretan Intermediate Water (CIW). Bottom circulations, in black, concerns the Levantine Deep Water (LDW), the Cretan Deep Water (CDW), the Southern Adriatic Deep Water (SAdDW), the North Adriatic Deep Water (NAdDW), the Adriatic Deep Water (ADW), the Eastern Mediterranean Deep Water (EMDW), the Tyrrhenian Deep Water (TDW), the Western Mediterranean Deep Water (WMDW), and the Mediterranean Outflow Water (MOW). Dashed lines indicate changes in paths of LIW and CIW, depending on the studied period [Roether et al., 1996].

dense water mass formation in all ocean regions is that it occurs intermittently, through a succession of short convective events lasting up to a few days and in a few specific areas of limited extent. These characteristic features make observation of convection a difficult task and its adequate representation in numerical models a major challenge. Despite these strong limitations, intermediate and deep water formation has been observed in several sites of the Mediterranean Sea (Figure 1). 
Table 1. Hydrographic Characteristics of the Main Mediterranean Intermediate and Deep Water Masses ${ }^{\mathrm{a}}$

\begin{tabular}{|c|c|c|c|}
\hline & $\sigma_{\theta}$ & $\theta\left({ }^{\circ} \mathrm{C}\right)$ & $S$ \\
\hline \multicolumn{4}{|c|}{ Levantine Basin (LIW/LDW) } \\
\hline Observations & $28.85<\sigma_{\theta}<29.18$ & $13.70<\theta<16.40$ & $38.70<S<39.20$ \\
\hline MED16-ECMWF & $29.04<\sigma_{\theta}<29.19$ & $13.60<\theta<15.48$ & $38.75<S<39.02$ \\
\hline MED16-ERA40 & $29.04<\sigma_{\theta}<29.16$ & $13.96<\theta<15.50$ & $38.83<S<39.03$ \\
\hline \multicolumn{4}{|c|}{ Aegean-Cretan Sea $(C I W / C D W)$} \\
\hline Observations (after EMT) & $29.00<\sigma_{\theta}<29.20$ & $14.30<\theta<15.20$ & $38.97<S<39.05$ \\
\hline MED16-ECMWF & $28.90<\sigma_{\theta}<29.35$ & $13.80<\theta<16.31$ & $38.50<S<39.07$ \\
\hline MED16-ERA40 & $28.90<\sigma_{\theta}<29.24$ & $13.80<\theta<16.10$ & $38.50<S<39.04$ \\
\hline \multicolumn{4}{|c|}{ Adriatic Sea $(A D W)$} \\
\hline Observations & $29.15<\sigma_{\theta}<29.20$ & $12.88<\theta<13.50$ & $38.59<S<38.73$ \\
\hline MED16-ECMWF & $28.95<\sigma_{\theta}<29.14$ & $12.50<\theta<13.53$ & $38.33<S<38.52$ \\
\hline MED16-ERA40 & $28.94<\sigma_{\theta}<29.10$ & $12.60<\theta<13.67$ & $38.30<S<38.47$ \\
\hline \multicolumn{4}{|c|}{ Gulf of Lion (WMDW) } \\
\hline Observations & $29.10<\sigma_{\theta}<29.12$ & $12.70<\theta<13.01$ & $38.40<S<38.57$ \\
\hline MED16-ECMWF & $29.04<\sigma_{\theta}<29.09$ & $12.85<\theta<13.62$ & $38.43<S<38.58$ \\
\hline
\end{tabular}

${ }^{a}$ According to Castellari et al. [2000], Theocharis et al. [2002], Manca et al. [2002, 2003, 2006], Petrenko et al. [2005], Schroeder et al. [2006, 2008], The LIWEX Group [2003], the CORIOLIS database, and the two simulations.

The Western Mediterranean Deep Water (WMDW) is formed in the Gulf of Lion [MEDOC Group, 1970; The THETIS Group, 1994]. The Adriatic Deep Water (ADW) is formed in the Adriatic Sea [Artegiani et al., 1997] through ventilation of the Southern Adriatic Deep Water (SAdDW), a regional water mass formed in the southern part of the Adriatic Sea in the socalled Sad Gyre (SG in Figure 1a), and the Northern Adriatic Deep Water (NAdDW) advected from its source region in the northern part of the Adriatic Sea [Manca et al., 2006]. The Levantine Intermediate/Deep Water (LIW/LDW) is formed in the northern part of the Levantine basin, mostly in the Rhodes Gyre (RG in Figure 1a) [Robinson et al., 1992; Sur et al., 1992; The LIWEX Group, 2003] and can be traced up to the Atlantic Ocean [Gascard and Richez, 1985]. Finally, the Cretan Intermediate/Deep Water (CIW/CDW) is formed in the Aegean-Cretan Sea [Theocharis et al., 1999]. All of these water masses can be recognized by their distinct hydrographic characteristics as shown in Table 1.

[3] Several key ingredients involving the atmospheric forcing appear to sustain the typical scenario leading to deep water formation as described, e.g., by MEDOC Group [1970]. This scenario occurs as a three-phase process: the preconditioning phase, the violent mixing phase, and the restratification phase. Concomitant observations of atmospheric forcing and convection depth in the Gulf of Lion suggest that the interannual variability of the convection can be largely interpreted as a response of the water column to the surface forcing during the destratification (mixing) phase, with large heat loss and strong wind stress contributing to enhancing the vertical mixing and deepening of the mixed layer [Mertens and Schott, 1998; Marshall and Schott, 1999]. The wind stress distribution is also crucial in maintaining a vigorous gyre-scale cyclonic circulation during the preconditioning phase at the onset of the convective season. A strong gyre circulation altogether helps maintaining a steady dense water dome with a weak stratification in its center and acts to confine the water parcels in the gyre interior where they can be exposed more persistently to the atmospheric forcing [Gascard, 1978; Lascaratos et al., 1993; Madec et al., 1996; Wu et al., 2000]. This preconditioning has been shown to be essential in the Gulf of Lion [Swallow and Gaston, 1973; Killworth, 1976; Gascard, 1978] where the wind stress curl works against the destabilizing effect of the baroclinic instability to maintain a wide and vigorous barotropic cyclonic circulation reinforced by bottom topography trapping [Madec et al., 1996; Jones and Marshall, 1993].

[4] Recent observations have shown that winter convection is highly variable on interannual to decadal time scales with regard to the localization and the depth of penetration of the dense water renewal [Mertens and Schott, 1998; Klein et al., 2000; Lopez-Jurado et al., 2005]. In the eastern Mediterranean Sea, decadal variability associated with the Eastern Mediterranean Transient [Roether et al., 1996] have been detected with two different regimes of thermohaline circulation corresponding to the Adriatic Sea or the AegeanCretan Sea being alternatively the major source of the Eastern Mediterranean Deep Water (EMDW). In the western Mediterranean, the northern basin has recently had an amplified response to climate variations [Schroeder et al., 2008].

[5] Numerical simulations of the Mediterranean Sea indeed show strong interannual variability of the convection in response to changes in atmospheric surface temperature and wind fields [Bozec et al., 2006; Somot et al., 2006]. Moreover, dedicated numerical works in realistic configurations for the whole Mediterranean Sea have stressed the crucial impact of the characteristic time scales of the atmospheric forcing on the convection variability [Castellari et al., 2000; Wu et al., 2000; Artale et al., 2002]. In particular, use of daily instead of monthly forcing in these simulations significantly increased the simulated volume of deep water formed [Castellari et al., 2000]. It should be stressed that these experiments were based on ocean models and atmospheric forcing of fairly low spatial resolution. As a consequence, water mass formation in the convection regions could not be adequately represented without applying undesirable corrections to air sea exchanges and in particular to the surface fresh water forcing. None of these studies investigated the impact of increasing the spatial resolution of the forcing. This impact is expected to be particularly strong in the Mediterranean Sea, where the convection is mainly forced by regional wind patterns such as the 
northerly Mistral and the northwesterly Tramontane winds extending across the western Mediterranean down to the African coast, the northeasterly Etesian winds in the eastern Mediterranean, or the Bora winds in the Adriatic Sea. The specificity of these wind regimes is that they are highly variable in time but also highly localized in space [Josey, 2003], which can have repercussions on the wind stress and heat flux distributions. Comparing different surface wind field data sets over the Mediterranean Sea in the recent period, Ruti et al. [2008] showed that a major source of error lies in the spatial resolution of the forcing, which can significantly modify the mean annual surface heat budget.

[6] The present study investigates the effect of the spatial distribution of the atmospheric forcing on dense water formation based on dedicated numerical simulations. Two companion simulations using the same high-resolution ocean model, the Mediterranean configuration MED16 [Béranger et al., 2004] of the OPA model [Madec et al., 1997] were forced by atmospheric forcing with different horizontal resolutions $(100 \mathrm{~km}$ and $\sim 50 \mathrm{~km})$. Additional sensitivity experiments were also used to investigate the separate effects of spatial and temporal smoothing of the forcing on the convection.

[7] The paper is organized as follows. Section 2 presents the numerical model configuration (section 2.1), the experimental setup of the two simulations (section 2.2), and then focuses on a description of the two atmospheric forcings (section 2.3). In section 3, a validation of the mean characteristics of the two simulations with regard to observations in the different convective basins is provided (section 3.1), and the characteristics of the convection between the two companion simulations are analyzed (section 3.2). Four major convection areas are considered: the Levantine basin, the Aegean-Cretan Sea, the Adriatic Sea, and the Gulf of Lion. A discussion on the particular case of the Gulf of Lion, supported by additional sensitivity experiments, is given in section 4. Section 5 presents some conclusions.

\section{Experimental Setup}

\subsection{Numerical Model Configuration}

[8] The MED16 model of the Mediterranean Sea [Béranger et al., 2004, 2005] has been developed in the framework of the Mercator project [Bahurel et al., 2002; Drillet et al., 2005]. The model domain extends from $11^{\circ} \mathrm{W}$ to $36^{\circ} \mathrm{E}$ and $30^{\circ} \mathrm{N}$ to $46^{\circ} \mathrm{N}$ (Figure 1a). Its horizontal resolution is $1 / 16^{\circ}$ in longitude and $1 / 16^{\circ} \cos (\lambda)$ in latitude ( $\lambda$ is the latitude), with 43 vertical levels on a stretched grid with layer thickness increasing from $6 \mathrm{~m}$ at the surface to $200 \mathrm{~m}$ at the bottom.

[9] MED16 is a regional version, dedicated to the Mediterranean Sea, of the primitive-equation numerical model Ocean Parallel (OPA) [Madec et al., 1997]. A biharmonic parameterization is used for horizontal eddy momentum and tracer diffusivity with associated coefficients equal to $-310^{9} \mathrm{~m}^{4} \mathrm{~s}^{-2}$. No-slip conditions are applied at the lateral boundaries. The vertical diffusivity for tracers and momentum is modeled with the turbulent kinetic energy closure scheme proposed by Blanke and Delecluse [1993]. In case of vertical static instabilities, the vertical diffusivity is increased to a threshold value of $1 \mathrm{~m}^{2} \mathrm{~s}^{-1}$. The fast barotropic gravity waves are filtered out using the rigid lid approximation.
[10] To help in analyzing simulation results, diagnostic fields have been calculated. First, the mixed layer depth, used as an indicator of the convection efficiency [Mertens and Schott, 1998], is diagnosed as the depth at which the vertical diffusivity coefficient corresponds to the threshold value taking care of vertical static instability. The sea surface height ( $\mathrm{SSH})$ is diagnosed through the integration of the surface pressure gradient, taking a reference level in the Ionian basin for the integration.

\subsection{Experimental Setup}

[11] The Mediterranean domain of MED16 was initialized from the MODB-4 winter potential temperatures $(\theta)$ and salinities $(S)$ climatology [Brankart and Brasseur, 1998]. The Atlantic Ocean is simulated as a closed domain extending from $37^{\circ}$ to $40^{\circ} \mathrm{N}$, and from $6^{\circ}$ to $11^{\circ} \mathrm{W}$, in which the threedimensional $\theta-\mathrm{S}$ fields are restored toward the Reynaud et al. [1998] seasonal climatology with a constant time scale of 2 days between $11^{\circ} \mathrm{W}$ and $8.5^{\circ} \mathrm{W}$, increasing eastward to 90 days between $8.5^{\circ} \mathrm{W}$ and $6^{\circ} \mathrm{W}$.

[12] The MED16 model was forced by daily atmospheric fields (see section 2.3) following the formalism described in Barnier [1998].

[13] 1. The flux boundary condition at the surface for the temperature is a function of the heat flux. The heat flux $Q$ includes the contribution of the climatic net heat flux $Q_{n e t}$ (sum of solar, infrared, latent, and sensible heat fluxes at the ocean surface) and a relaxation term, which models the feedback of the ocean on the air-sea fluxes. The surface boundary condition for the temperature is written as follows:

$$
\left.K_{V} \frac{d T}{d z}\right|_{z=0}=\frac{1}{\rho C_{p}} Q=\frac{1}{\rho C_{p}}\left[Q_{n e t}+\lambda_{T}\left(T_{s}^{c l i m}-T_{S}^{o c e a n}\right)\right]
$$

with $z$ the vertical coordinate, $K_{v}$ the vertical diffusivity coefficient, $\rho$ the density of seawater, and $C_{p}$ the specific heat of seawater. In the relaxation term, the temperature at the top level of the model, $T_{S}^{\text {ocean }}$, is restored to $T_{s}^{\text {clim }}$ the sea surface temperature from the Reynolds [1988] climatology with a time scale in the range of 8 to 30 days corresponding to a coefficient $\lambda_{T}$ varying from $40 \mathrm{~W} \mathrm{~m}^{-2} \mathrm{~K}^{-1}$ in summer to $10 \mathrm{~W} \mathrm{~m}^{-2} \mathrm{~K}^{-1}$ in winter.

[14] 2. The flux boundary condition at the surface for the salinity is modeled as a virtual salt flux and a correction is added to avoid salinity drift in the simulation:

$$
\left.K_{V} \frac{d S}{d z}\right|_{z=0}=(E-P-R) S_{S}^{o c e a n}+\lambda_{S}\left(S_{S}^{c \lim }-S_{S}^{\text {ocean }}\right),
$$

with $E$ the evaporation, $P$ the precipitation, $R$ the river discharge (in $\mathrm{m} \mathrm{s}^{-1}$ ), $S_{S}^{\text {ocean }}$ the ocean salinity of the first vertical level of the model, $S_{S}^{c l i m}$ the sea surface salinity of the MODB-4 climatology, and $\lambda_{S}$ a constant coefficient corresponding to a relaxation time scale of about 8 days for a top layer thickness of $6 \mathrm{~m}$.

[15] Starting from rest, a spinup period of 11 years extending from 1 January 1987 to 28 February 1998 was carried out in which the MED16 model was forced by the atmospheric surface fields from the ECMWF reanalysis, hereafter ERA40, which has an equivalent horizontal resolution of about $100 \mathrm{~km}$ [Uppala et al., 2005]. After the spinup period, from 1 March 1998 onward, two simulations 
Table 2. Summary of the Experiments

\begin{tabular}{llll}
\hline Exp & \multicolumn{2}{c}{ Name } & Fluxes \\
\hline & MED16-ECMWF & $E C M W F$ & $E C M W F$ \\
& MED16-ERA40 & $E R A 40$ & $E R A 40$ \\
1 & MED16-ERA40_HIGHWIND & $E R A 40$ & $E R A 40$ winds which intensity is multiplied by a factor 1.5 \\
2 & MED16-ERA40_WIND-ECMWF_FLUX & $E C M W F$ & $E R A 40$ \\
3 & MED16-ERA40_FLUX-ECMWF-WIND & $E R A 40$ & $E C M W F$ \\
4 & MED16_ECMWF_WIND_1DEG & $E C M W F$ & $E C M W F$ winds smoothed spatially on a $1^{\circ} \times 1^{\circ}$ grid equivalent to ERA40 \\
5 & MED16-ECMWF_WIND_5DAY & $E C M W F$ & $E C M W F$ winds low-pass filtered with a time window of 5 days \\
\hline
\end{tabular}

were run in parallel for an additional 4 year period (up to April 2002), each of them using a distinct atmospheric forcing (Table 2). The control experiment, hereafter MED16-ERA40, is a continuation of the spinup experiment and was thus forced by the ERA40 atmospheric forcing fields. In the companion experiment, hereafter MED16-ECMWF, the model was instead forced by the recent ECMWF analyzed atmospheric fields, hereafter $E C M W F$, which have a finer horizontal resolution, evolving from about $60 \mathrm{~km}$ in 1998 to $40 \mathrm{~km}$ in 2002 (for more details, see Ruti et al. [2008]). The 4 year integration period has been chosen as the common period available between the two atmospheric data sets. (ECMWF has been available since March 1998, while ERA40 was not available beyond 2002.) These two atmospheric models are run by the same research center (ECMWF) and are based on a similar semispectral dynamic code. The data assimilated in the ERA40 reanalysis come from the database assimilated in the ECMWF operational model. The two versions of the model use close assimilation methods. For the purpose of the present analysis, however, we assume that most of the differences identified in the surface forcings between the two products are mostly to be attributed to their different spatial resolution.

\subsection{Description of the Atmospheric Forcing (March 1998 to April 2002)}

[16] The monthly time series derived from the ERA40 and the $E C M W F$ atmospheric fields separately averaged over the western and eastern Mediterranean (Figure 2) are in relatively good agreement with those reported in the literature [Castellari et al., 2000; Mariotti et al., 2002]. In the two regions, the monthly mean wind stress modulus and the net heat flux (strongly dominated by evaporation) show similar well-marked seasonal cycles modulated by some interannual variations. The wind stress (Figure 2a) is minimal (about $0.03 \mathrm{~N} \mathrm{~m}^{-2}$ ) between August and October and maximal (up to $0.14 \mathrm{~N} \mathrm{~m}^{-2}$ ) between November and February. The net heat flux (Figure $2 \mathrm{~b}$ ) roughly presents similar seasonal variations with a maximum loss (between 150 and $250 \mathrm{~W} \mathrm{~m}^{-2}$ ) between November and January, which generally coincides with that of the wind stress. The seasonal cycles of the wind stress and the heat flux are generally shifted by up to 2 months between the western and eastern Mediterranean. Monthly heat losses are of comparable magnitude in the two regions.

[17] The air-sea heat flux in $E C M W F$ shows higher minima and maxima than ERA40 with typical differences reaching up to $30 \mathrm{~W} \mathrm{~m}^{-2}$ (Figure 2b). In all seasons, the wind stress is larger in $E C M W F$ than in $E R A 40$, with differences reaching up to $0.03 \mathrm{~N} \mathrm{~m}^{-2}$ (Figure 2a), particularly in winter.

[18] To compare the high-frequency (typically a few days) variability of the forcing between the two experiments, standard deviations of the daily fields with respect to their monthly mean have been estimated. Mean standard deviations of each atmospheric field are thus constructed by averaging the standard deviations over the 48 months for both simulations. The four main areas of winter convection (the Gulf of Lion, the Adriatic Sea, the Levantine basin, and the Aegean-Cretan Sea) are clearly identified as the regions with the highest values of the mean standard deviation of both the wind stress and the heat flux (Figure 3). For example, in $E C M W F$, the standard deviations reach $290 \mathrm{~W} \mathrm{~m}^{-2}$ in the Gulf of Lion between $\left[41.5-42.5^{\circ} \mathrm{N}\right]$ and $\left[3.5-4.5^{\circ} \mathrm{E}\right]$, $250 \mathrm{~W} \mathrm{~m}^{-2}$ in the northern Adriatic Sea and $370 \mathrm{~W} \mathrm{~m}^{-2}$ in the northeastern Aegean-Cretan Sea. Therefore, the magnitude of the daily variations of the air-sea fluxes in the convection areas are of the same order as the seasonal amplitudes of the monthly net heat flux (Figure 2b). The standard deviations are, however, larger in the ECMWF data set than in ERA40, with values in ERA40 being only $70-80 \%$ that of $E C M W F$ for the net heat flux in the major convection areas. The same remark holds for the wind stress with values in ERA40 being only $50-80 \%$ that of $E C M W F$. The larger differences in the wind stress and heat flux occur in the Gulf of Lion and in the northern Aegean Sea, suggesting that the high-frequency variability in these regions is related to specific atmospheric events associated with the regional wind patterns mentioned in the introduction. As an exception, the standard deviations of the wind stress and the heat flux around the Crete Island are higher by $10 \%$ in ERA40 than in ECMWF.

[19] Differences in the wind stress are particularly marked in the Gulf of Lion, where the standard deviation maximum occupies a large area of $200 \mathrm{~km}$ by $300 \mathrm{~km}$ centered around $42^{\circ} \mathrm{N}-4^{\circ} \mathrm{E}$, while in $E R A 40$, such a marked feature does not exist. We postulate in the following section that this feature is representative of the variability associated with mesoscale atmospheric patterns which is better constrained by land orography in ECMWF than in ERA40. We also note that the maximum of the heat flux in ERA40 is located along the coast rather than offshore and above the deep convection area.

\section{Comparative Evaluation of the MED16-ERA40 and MED16-ECMWF Experiments}

\subsection{Global Characteristics}

[20] The two experiments produce similar surface circulations (not shown), which are consistent with results of earlier simulations using MED16 (see Béranger et al. [2005]). The transport of LIW and its seasonal variation in the Channel of Sicily and in the Strait of Corsica are in good agreement with observations reported by Astraldi and Gasparini [1992] and Astraldi et al. [1999]. The Algerian Gyres and the Sardinian 

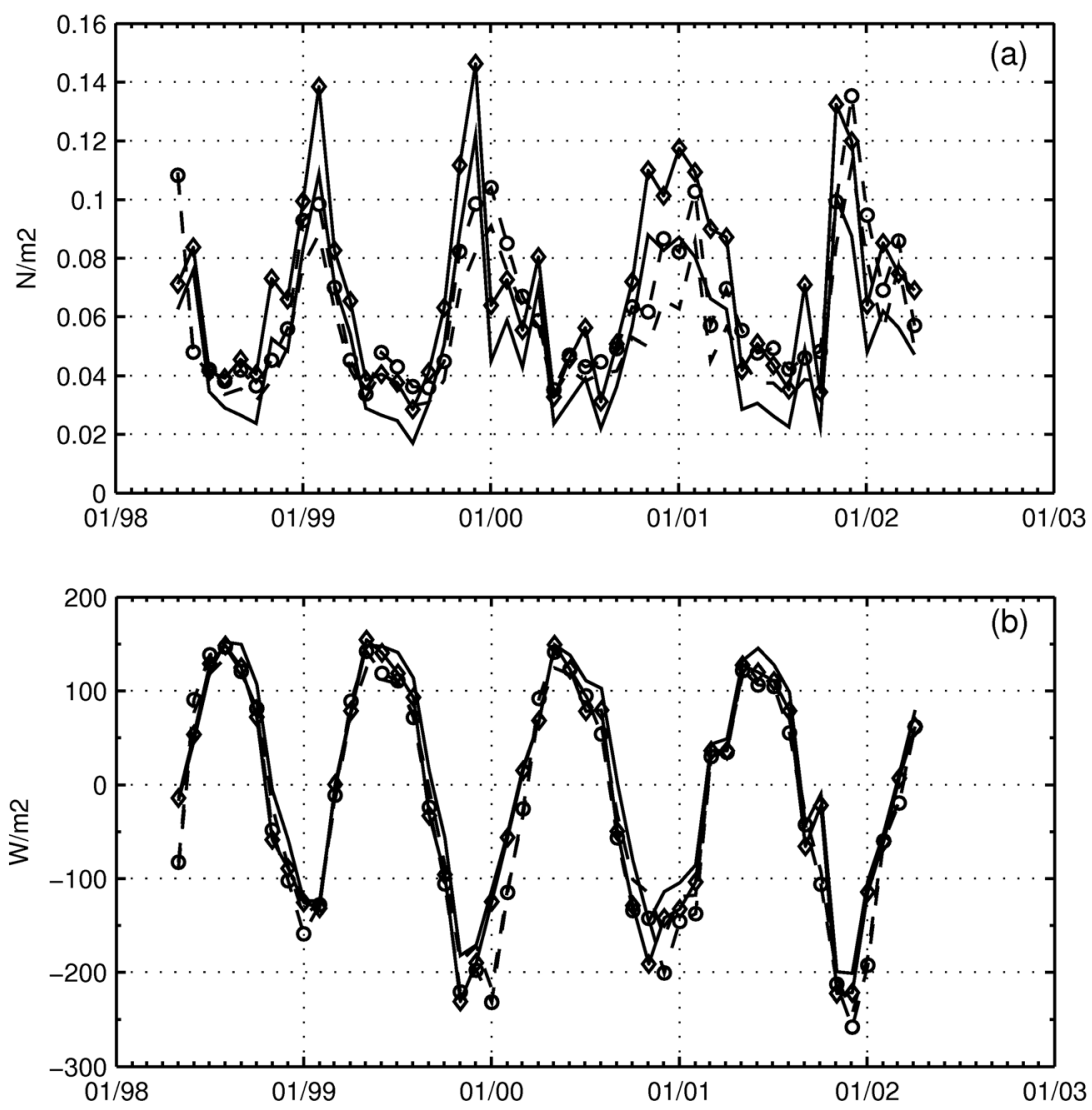

Figure 2. Monthly mean time series of (a) wind stress modulus $\left(\mathrm{N} \mathrm{m}^{-2}\right)$ and (b) net heat flux $\left(\mathrm{W} \mathrm{m}^{-2}\right)$ averaged over the western Mediterranean in MED16-ECMWF (diamond full line) and MED16-ERA40 (full line), and averaged over the eastern Mediterranean in MED16-ECMWF (circle dashed line) and MED16-ERA40 (dashed line). The time series are shown over the simulation period May 1998 to April 2002.

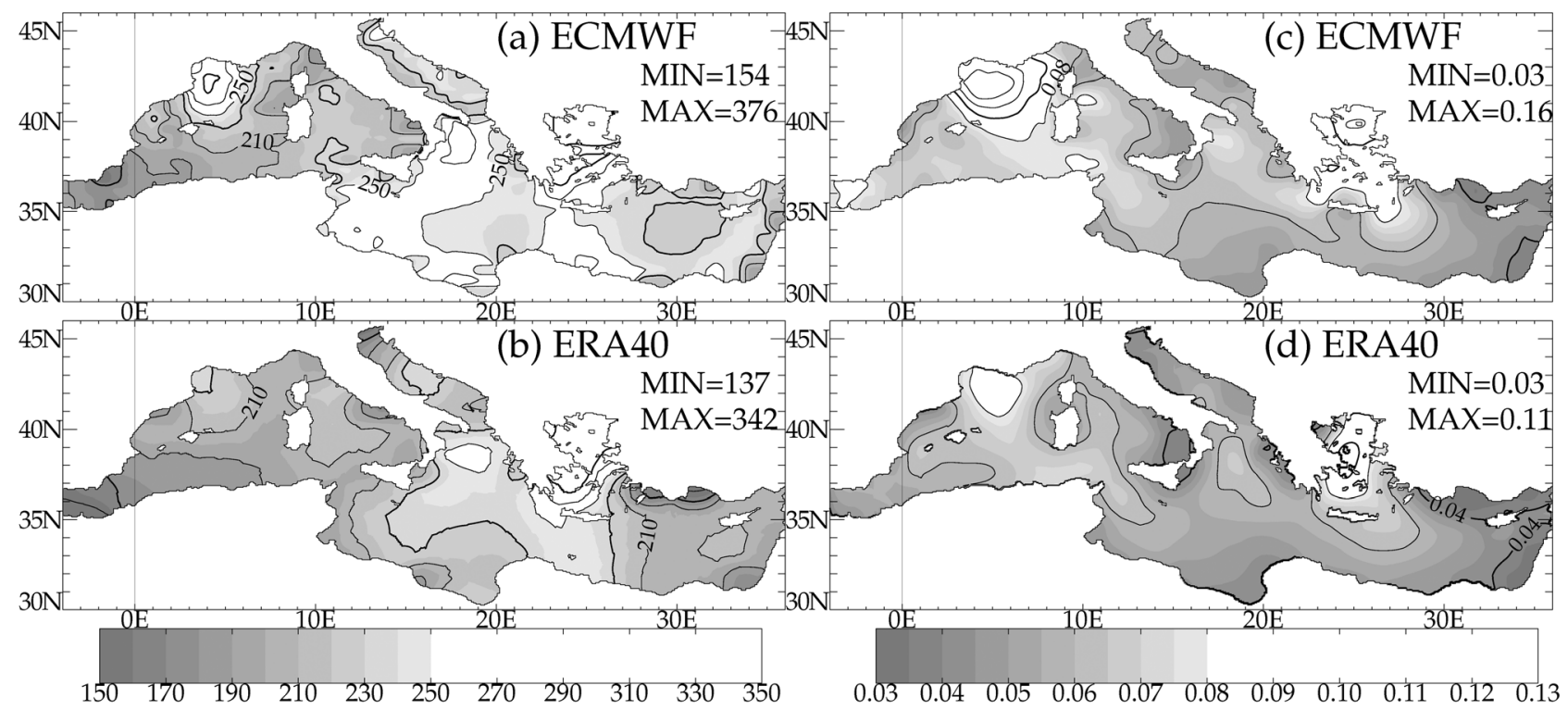

Figure 3. Mean standard deviations for the 4 year period May 1998 to April 2002 of (a and b) the daily net heat flux (black contours from 130 to 320 per $20 \mathrm{~W} \mathrm{~m}^{-2}$ ) and (c and d) the daily wind stress modulus (black contours from 0 to 0.16 by $0.02 \mathrm{~N} \mathrm{~m}^{-2}$ ) for ECMWF (Figures 3a and 3c) and ERA40 (Figures 3b and $3 d$ ). 

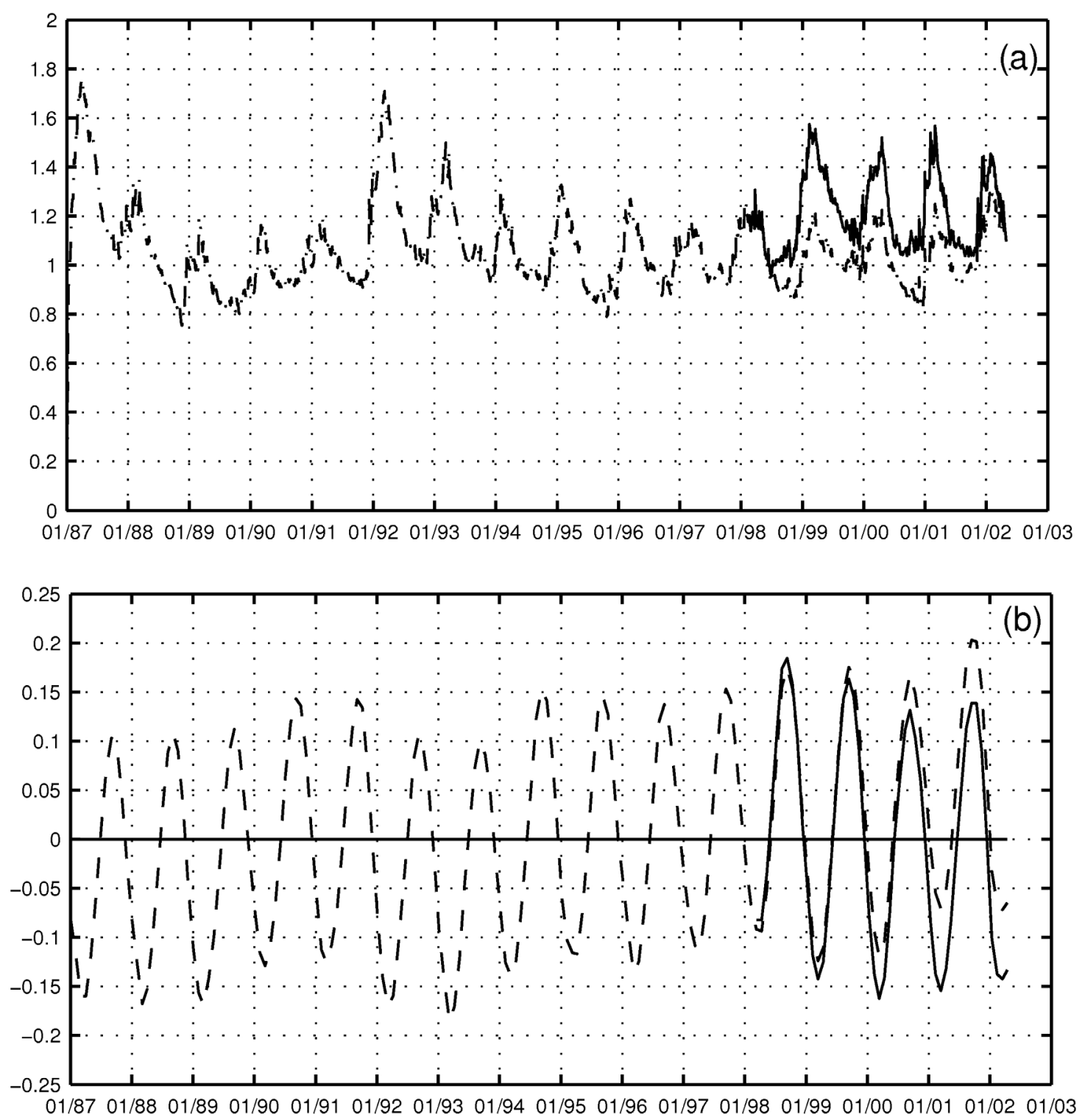

Figure 4. Time series of (a) the daily turbulent kinetic energy averaged over the whole MED16 domain (in $10^{-4} \mathrm{~m}^{2} \mathrm{~s}^{-2}$ ) and (b) the monthly volume mean temperature anomalies of the entire Mediterranean (in ${ }^{\circ} \mathrm{C}$ ), in MED16-ERA40 (dashed line) and MED16-ECMWF (full line). For the period $1998-2002$, the volume mean temperature is $13.73^{\circ} \mathrm{C}$ in MED16-ECMWF and $13.77^{\circ} \mathrm{C}$ in $\mathrm{MED} 16-$ ERA40, showing a difference of $0.04^{\circ} \mathrm{C}$.

Eddies [Testor et al., 2005a], are similar to those observed by Testor et al. [2005b]. The structure of the AW boundary current in the Levantine basin resembles that described by Alhammoud et al. [2005]. The turbulent kinetic energy averaged over the whole model domain shows a high seasonal variability in both experiments (Figure 4a). The energy level is however higher in MED16-ECMWF, which simulates an intermediate circulation in the northwestern Mediterranean comparing well with the float trajectories reported by Taillandier et al. [2006]. Differences also exist between the volume mean temperature of the entire Mediterranean simulated in the two experiments, with MED16ECMWF showing colder temperatures throughout the year (Figure 4b).

\subsection{Variability of the Convection}

\subsubsection{Definition of Convection Indices}

[21] Several parameters have been defined to characterize the convection activity in the two simulations: the mixed layer depth, the horizontal extent of the convective regions, and the rate of deep water formation. We show that the three parameters provide consistent information on the interannual variability of the convection as well as on its contrasted representation between the control and companion experiments.

[22] To characterize the vertical extent of the convection, we use the maximum of the daily mixed layer depth. This maximum is calculated at each model grid point based on the 4 years of the simulation. Within each convective area, a 
Table 3. Mean Quantities Computed by the Two Models in the Major Convection Areas ${ }^{\mathrm{a}}$

\begin{tabular}{|c|c|c|c|c|c|c|c|c|}
\hline \multirow[b]{2}{*}{ Winter } & \multicolumn{2}{|c|}{$R(S v)$} & \multicolumn{2}{|c|}{$\bar{D}(\mathrm{~m})$} & \multicolumn{2}{|c|}{$\phi(\mathrm{km})$} & \multicolumn{2}{|c|}{$\phi / \phi^{T}(\%)$} \\
\hline & $\begin{array}{l}\text { MED16- } \\
\text { ECMWF }\end{array}$ & $\begin{array}{l}\text { MED16- } \\
\text { ERA40 }\end{array}$ & $\begin{array}{l}\text { MED16- } \\
\text { ECMWF }\end{array}$ & $\begin{array}{c}\text { MED16- } \\
\text { ERA40 }\end{array}$ & $\begin{array}{l}\text { MED16- } \\
\text { ECMWF }\end{array}$ & ERA40 & $\begin{array}{l}\text { MED16- } \\
\text { ECMWF }\end{array}$ & $\begin{array}{r}\text { MED16- } \\
\text { ERA40 }\end{array}$ \\
\hline \multicolumn{9}{|c|}{ Levantine Basin } \\
\hline 1999 & 0.05 & 0.11 & 328 & 359 & 107 & 151 & 14 & 37 \\
\hline 2000 & 0.30 & 0.12 & 574 & 349 & 207 & 166 & 52 & 45 \\
\hline 2001 & 0.40 & 0.06 & 413 & 363 & 228 & 89 & 63 & 13 \\
\hline 2002 & 0.05 & 0.11 & 353 & 373 & 110 & 135 & 14 & 30 \\
\hline \multicolumn{9}{|c|}{ Aegean-Cretan Sea } \\
\hline 1999 & 0.12 & 0.11 & 348 & 349 & 137 & 127 & 23 & 23 \\
\hline 2000 & 0.59 & 0.48 & 398 & 391 & 272 & 250 & 93 & 88 \\
\hline 2001 & 0.23 & 0.02 & 367 & 322 & 171 & 56 & 37 & 4 \\
\hline 2002 & 0.26 & 0.11 & 390 & 344 & 235 & 170 & 69 & 41 \\
\hline \multicolumn{9}{|c|}{ Adriatic Sea } \\
\hline 1999 & 0.19 & 0.08 & 400 & 358 & 159 & 107 & 87 & 72 \\
\hline 2000 & 0.24 & 0.07 & 458 & 383 & 155 & 98 & 84 & 60 \\
\hline 2001 & & & & & & & & \\
\hline 2002 & 0.07 & 0.02 & 374 & 327 & 124 & 55 & 53 & 19 \\
\hline \multicolumn{9}{|c|}{ Gulf of Lion } \\
\hline 1999 & 0.18 & & 742 & & 111 & & 59 & \\
\hline 2000 & 0.08 & & 624 & & 107 & & 55 & \\
\hline 2001 & 0.10 & & 633 & & 94 & & 43 & \\
\hline 2002 & 0.01 & & 556 & & 38 & & 7 & \\
\hline
\end{tabular}

${ }^{\mathrm{a}} R$ is the rate of deep water formation in sverdrup $\left(1 \mathrm{~Sv}=10^{-6} \mathrm{~m}^{3} \mathrm{~s}^{-1}\right), \bar{D}$ is the mean depth of the winter extent $A$ (in meters), $\phi$ is the equivalent diameter of a circle which has a surface equal to those of $A$ in kilometers, $\phi / \phi^{T}$ is the ratio of the winter extent $A$ and of the union of the 4 winter values of $A$ in percentage. The $\phi^{T}$ values are for MED16-ECMWF (MED16-ERA40) $\phi^{T}=289 \mathrm{~km}^{2}\left(\phi^{T}=248 \mathrm{~km}^{2}\right)$ in the Levantine Basin, $\phi^{T}=$ $283 \mathrm{~km}^{2}\left(\phi^{T}=248 \mathrm{~km}^{2}\right)$ in the Aegean-Cretan Sea, $\phi^{T}=171 \mathrm{~km}^{2}\left(\phi^{T}=126 \mathrm{~km}^{2}\right)$ in the Adriatic Sea and $\phi^{T}=144 \mathrm{~km}^{2}$ in the Gulf of Lion.

regional maximum, hereafter $D$, of the daily mixed layer depth is also defined as an index of the regional convection. Additionally, we chose to identify deep convective mixing using a critical mixed layer depth, hereafter $D_{c}$, defined as the level at which the convection penetrates the deep water masses after crossing the LIW core, which is different in the two basins. The depth $D_{c}$ corresponds to a decrease in salinity of 0.02 situated just $100 \mathrm{~m}$ below the intermediate salinity maximum of the LIW core. A larger value of $D_{c}$ $(500 \mathrm{~m})$ is thus selected in the western Mediterranean compared with the eastern Mediterranean $\left(D_{c}=300 \mathrm{~m}\right)$.

[23] To characterize the horizontal extent of the convection, we use the area of the domain in which the daily mixed layer is deeper than the critical depth, $D_{c}$, computed each day in the four major convective regions. The envelope, hereafter $A$, of these daily areas for each winter (January to March) provides a measure of the horizontal extent of the convection, that is, the area where deep convection $\left(D>D_{c}\right)$ occurred at least once for a given winter. This extent can be converted into an equivalent diameter $\phi=2 \sqrt{A / \pi}$ (Table 3 ). The total area, hereafter $A^{T}$, defined as the envelope of the four winter areas $A$, provides a measure of the convection extent for the 4 year simulation period. Its equivalent diameter is $\phi^{T}$. The ratio $\phi / \phi^{T}$ calculated for each year of the sensitivity and control experiments (Table 3) can be used as an index of the relative intensity of the convection for a given year.

[24] Finally, the convection intensity is measured by the mean annual rate of deep water formation, hereafter $R$, obtained by dividing by a year the maximum value of the average daily volumes of water homogenized between the surface and a depth greater than $D_{c}$. We did not choose to apply Walin's method as discussed in Somot et al. [2006]. Our method is more similar to the method based on a threshold density value as described in Castellari et al. [2000].

\subsubsection{Regional Distribution of the Convection}

[25] In both experiments, the horizontal distribution of the maximum of the daily mixed layer depth over the 4 years of model integration shows distinct regions of deep mixed layers (Figure 5) corresponding to the convection areas already identified in Figure 3. In particular, the three major convection areas of the eastern Mediterranean are well identified in the two simulations. However, the simulated mixed layer depths are generally higher in MED16-ECMWF than in MED16-ERA40. The differences are particularly large in the Levantine basin and even more in the Gulf of Lion. If one excepts the latter region, both experiments simulate maximum mixed layer depths in good agreement with the climatological estimates as reported by d'Ortenzio et al. [2005].

[26] In the Levantine basin, our two experiments show convection occurring in mesoscale features present all over the basin, in agreement with Lascaratos and Nittis [1998] simulation results and the observations by The LIWEX Group [2003]. The locations of the deepest mixed layer, however, differ between the two simulations. Mostly located to the northeast of the Rhodes Gyre, around $35^{\circ} \mathrm{N}-29^{\circ} \mathrm{E}$, in MED16-ERA40 (Figure 5b), the deepest mixed layers are shifted by $1^{\circ}$ westward, around $35^{\circ} \mathrm{N}-28^{\circ} \mathrm{E}$, in MED16ECMWF (Figure 5a). More important, the two simulations disagree on the interannual variability of the maximum mixed layer depth $D$ : While the mixed layer reaches only intermediate depths with small year-to-year changes in MED16-ERA40, distinct episodes of deep convection were observed in MED16-ECMWF in the winters of 2000 and 2001 (Figure 6a), leading to the formation of LDW. The convection depths (1200 m in 2000 and $800 \mathrm{~m}$ in 2001) simulated in MED16-ECMWF are in better agreement with the D'Ortenzio et al. [2005] climatological database and the 


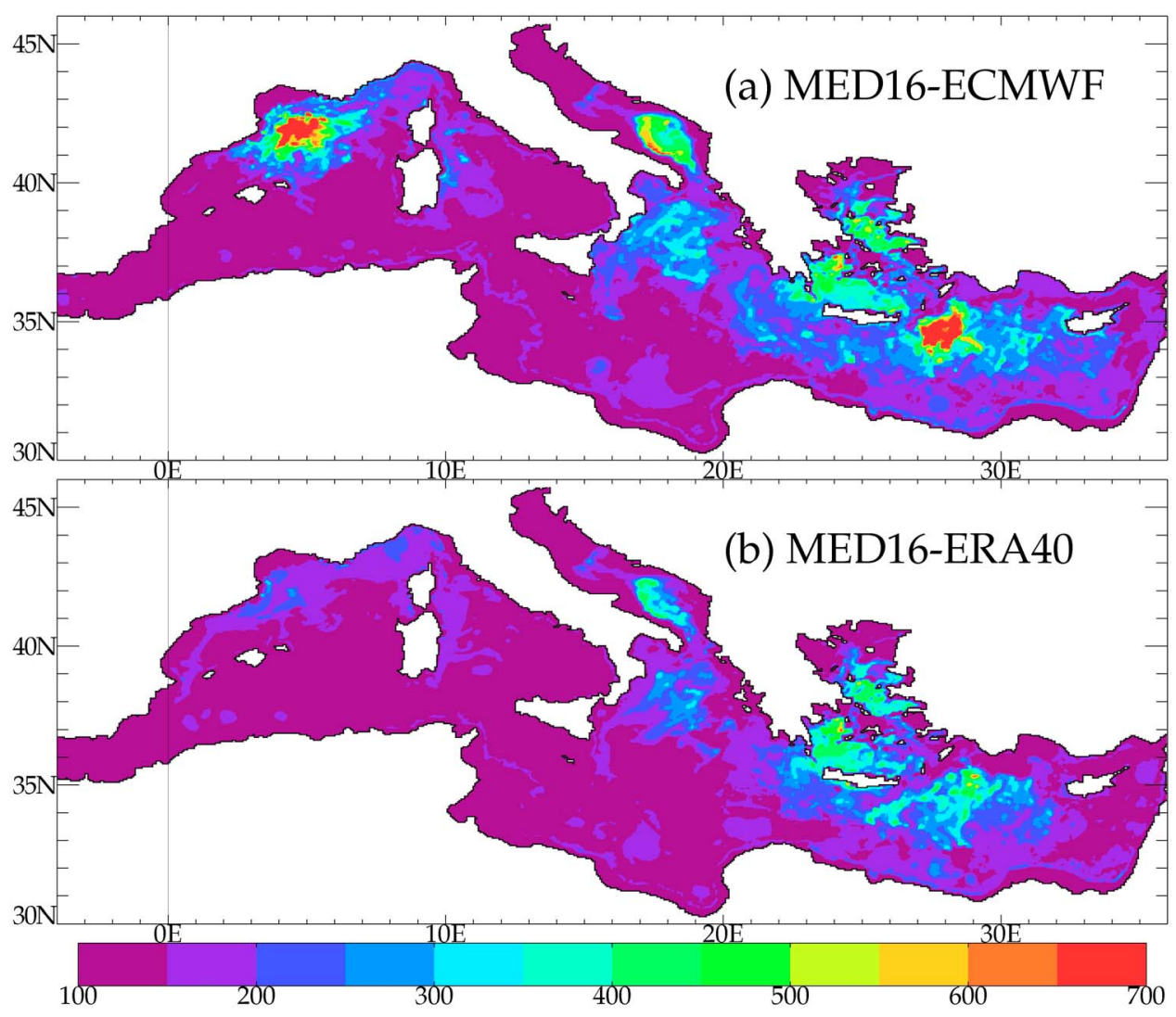

Figure 5. Horizontal distribution of the maximum of the mixed layer depth (in meters) over the years of the common simulation period (May 1998 to April 2002) in (a) MED16-ECMWF and (b) MED16ERA40. The values of the regional maximum of the mixed layer depth, $D$, for each area in MED16ECMWF (MED16-ERA40 respectively) are $1199 \mathrm{~m}(640 \mathrm{~m})$ in the Levantine basin, $747 \mathrm{~m}(658 \mathrm{~m})$ in the Aegean-Cretan Sea, $740 \mathrm{~m}(545 \mathrm{~m})$ in the Adriatic Sea, and $1394 \mathrm{~m}$ (362 m) in the Gulf of Lion.

LIWEX observations [The LIWEX Group, 2003]. Even if the densities of the water masses ventilated at depth greater than $D_{c}$ (29.04-29.19, Table 1) fall within the observational range, the LIW tongue in the Cretan Passage (not shown) is too fresh by $0.04 \mathrm{psu}(38.90-38.92 \mathrm{psu}$ instead of 38.92-38.96 psu) and too shallow by $100 \mathrm{~m}(100-150 \mathrm{~m}$ instead of $200 \mathrm{~m}$ depth) in both simulations compared with the Manca et al. [2003] and Theocharis et al. [2002] observations.

[27] In the Aegean-Cretan Sea (Figure 6b), the dense waters are formed in restricted areas around Skyros and Chios (location 2 in Figure 1a), between $37.5^{\circ} \mathrm{N}$ and $39.5^{\circ} \mathrm{N}$, in the Cyclades Plateau (location 1 in Figure 1a) at about $24^{\circ}$ $\mathrm{E}-37^{\circ} \mathrm{N}$, and occasionally in the southern Aegean-Cretan Sea (Figure 5). These locations are roughly in agreement with the numerical simulations carried out by Nittis et al. [2003]. The maximum values of the mixed layer depth never reach depths greater than $750 \mathrm{~m}$ in any of the two simulations. This result is in agreement with the observations made after the Eastern Mediterranean Transient, in 1998, showing a reduced volume of warm and fresh transitional Mediterranean water in the Cretan Sea due to local ventilation and southward advection of intermediate waters coming from the Aegean Sea [Theocharis et al., 2002]. As noted for the LIW characteristics, the core of the CIW between 200 and $500 \mathrm{~m}$ in the northern Ionian basin at $39.5^{\circ} \mathrm{N}$ is not dense enough, being too fresh (by $0.02 \mathrm{psu}$ ) and too warm compared with the observations collected in 1999 [Manca et al., 2003] or in 2002 [Manca et al., 2006].

[28] In the southern Adriatic Sea, a convective zone is clearly identified in the Sad Gyre over an area of about $150 \mathrm{~km}$ in diameter (Figure 5). Several mesoscale convective features are seen, mostly along the front separating the Sad Gyre off the eastern coast of Italy (Figure 7), in agreement with the Manca et al. [2002] observations and Mantziafou and Lascaratos [2004] results based on a $1 / 20^{\circ}$ numerical simulation. The interannual variability of $D$ (Figure 6c) is very similar in MED16-ERA40 and MED16-ECMWF, with a systematic offset of 100 to $200 \mathrm{~m}$ in the mixed layer depth maximum in MED16-ECMWF. The latter simulation gives maximum convection depths of $250 \mathrm{~m}, 650 \mathrm{~m}$, and $700 \mathrm{~m}$, in 1998, 1999, and 2002, respectively, all values in good agreement with the previous observations [Manca et al., 2002; Cardin and Gacic, 2003]. The geographical distribution of the maximum mixed layer depth in winter 2000 is in better agreement with the observations of the CORIOLIS database (The CORIOLIS database, http://www.coriolis.eu. org) in MED16-ECMWF than in MED16-ERA40 (Figure 7). Nevertheless, the density of the bottom SadDW (29.14) in winter 1999 does not compare well with the observed value of 29.19 [Manca et al., 2002, their transect D in Figure 12b, bottom]. The ADW outflow, a tongue characterized by a minimum of temperature and salinity against the sill of the 

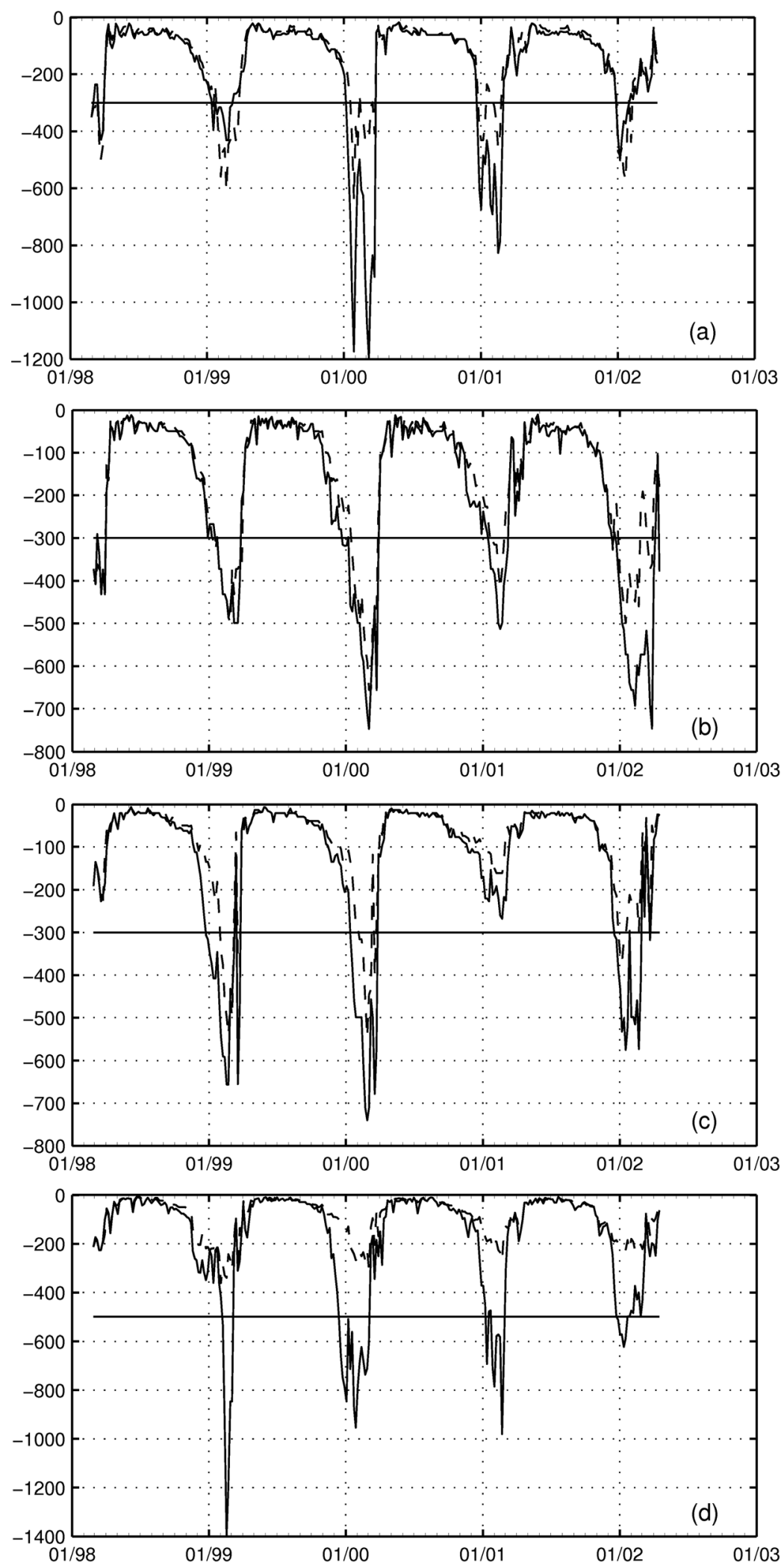

Figure 6. Time series of the regional maximum of the mixed layer depth, $D$, (in meters) for the 4 years of the simulation period, based on 5 day averages in MED16-ERA40 (dashed line) and MED16-ECMWF (full line): (a) Levantine basin, (b) Aegean-Cretan Sea, (c) Adriatic Sea, and (d) Gulf of Lion. The $D_{c}$ value is indicated by the black horizontal line. 


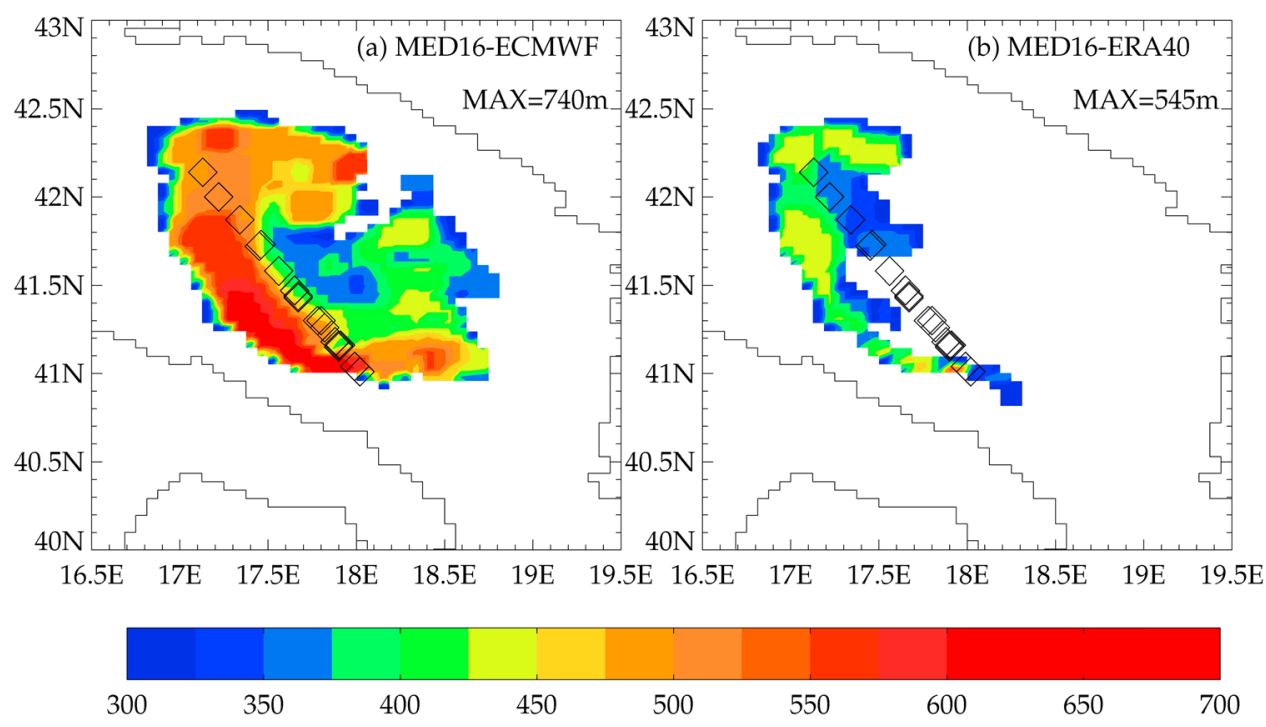

Figure 7. Maximum of the daily mixed layer depth (in meters) over the winter 2000 in the Adriatic Sea in (a) MED16-ECMWF and (b) MED16-ERA40. Diamonds correspond to homogeneous temperature profiles identified in the CORIOLIS database between January and March 2000. Only depths larger than $D_{c}=300 \mathrm{~m}$ are plotted.

Channel of Otranto (not shown) [Manca et al., 2003, 2006] is not simulated either. The inappropriate SadDW characteristics are to be attributed to the climatological initial conditions of the simulation which led to a convection depth not greater than $450 \mathrm{~m}$ during the spinup. It should be mentioned that only in MED16-ECMWF does a tongue of ADW characterized by a horizontal extent of $\sim 100 \mathrm{~km}$ (not shown) outflow from the Adriatic Sea in winter 2002, which is consistent with the greater mixed layer depth maximum (Figure 6c) and the presence of a southward flow of NadDW in that simulation.

[29] In the Gulf of Lion, only MED16-ECMWF is able to simulate deep convection events, reaching every year $600 \mathrm{~m}$ or deeper (Figures 5a and 6d). Convection takes place within a cyclonic gyre centered about $42^{\circ} \mathrm{N}-5^{\circ} \mathrm{E}$ (Figure 5a). The deepest convection occurs in 1999, and the corresponding mixed layer depth is in agreement with the only deep profile collected during the MOOGLI3 cruise (http://www.com. univ-mrs.fr/PNEC/MOOGLI, http://www.ifremer.fr/sismer/ program $/$ seasearch $/$ htql/campagne.htql).in the same period (Figure 8a). In that year, the simulated salinity of the WMDW trapped in the mesoscale convective features is $\mathrm{S}=38.47$ 38.50 , which is too low compared with the value of 38.52 in Petrenko et al. [2005] observations, leading to a too light water mass with density of 29.09 [Béranger et al., 2009] instead of 29.10. The spatial distribution and extent of the homogenized patch in winter 2000 compare well with the observations of the CORIOLIS database for the same year (Figure 8b), although the water mass is too warm and too fresh compared with the observation (Table 1). For this 4 year period, no mixed layer reaches deeper than 1,400 m (Figure 6d). There are no observations corresponding to the simulation period, but the simulated convection depth is always too small when considering observations from other years which indicate convection depths of about $1600 \mathrm{~m}$ in 1992 [The THETIS Group, 1994], $2000 \mathrm{~m}$ in 1987 [Schott and Leaman, 1991], or $2400 \mathrm{~m}$ in 2005 [Schroeder et al., 2008]).
Indeed, when the MED16-ECMWF simulation was extended beyond 2002, the model revealed it was able to simulate convection down to the bottom of the Gulf of Lion in 2005 [Béranger et al., 2009]. The comparatively shallow mixed layer depths in MED16-ECMWF can be partly explained by a too strong vertical stratification in the initial state of the experiment at the end of the spinup period forced by the ERA40 forcing fields. Such a strong stratification, present at the beginning of each winter, would prevent convection from reaching the bottom, despite intense surface heat loss, a scenario also mentioned by Somot et al. [2006].

\subsubsection{Variability of the Convection Based}

\section{on the Convection Indices}

[30] The timing of the different phases of the convective events is similar in the two experiments (Figure 6). The winter convection process generally starts between early November and early December, consisting of the mixing of the upper layer waters through mixed layer deepening down to intermediate depths $\left(D<D_{c}\right)$. This phase lasts 1-2 months, until mid-December to mid-January, when the mixed layer becomes generally deeper than $D_{c}$. Then a period of deep convection follows, which lasts between 1 and 3 months, depending on the year and contains several (one to three) successive deep mixing events (Figure 6). A quick restratification phase then generally follows in March. Intermediate or deep water masses are formed every winter in all major convection sites of the eastern Mediterranean, except in winter 2001 in the Adriatic Sea as mentioned by Book et al. [2005]. The interannual variability of the convection depth is roughly in phase in the three convection sites of the eastern Mediterranean, where the deepest $D$ is reached in winter 2000 (Figures 6a, 6b, and 6c), but it is somewhat different in the western Mediterranean, where the deepest $D$ is observed in winter 1999 in MED16-ECMWF (Figure 6d).

[31] The time evolution of the mixed layer depth within each convective area and based on the regional maximum $D$ confirms the different mixed layer behaviors in the two si- 


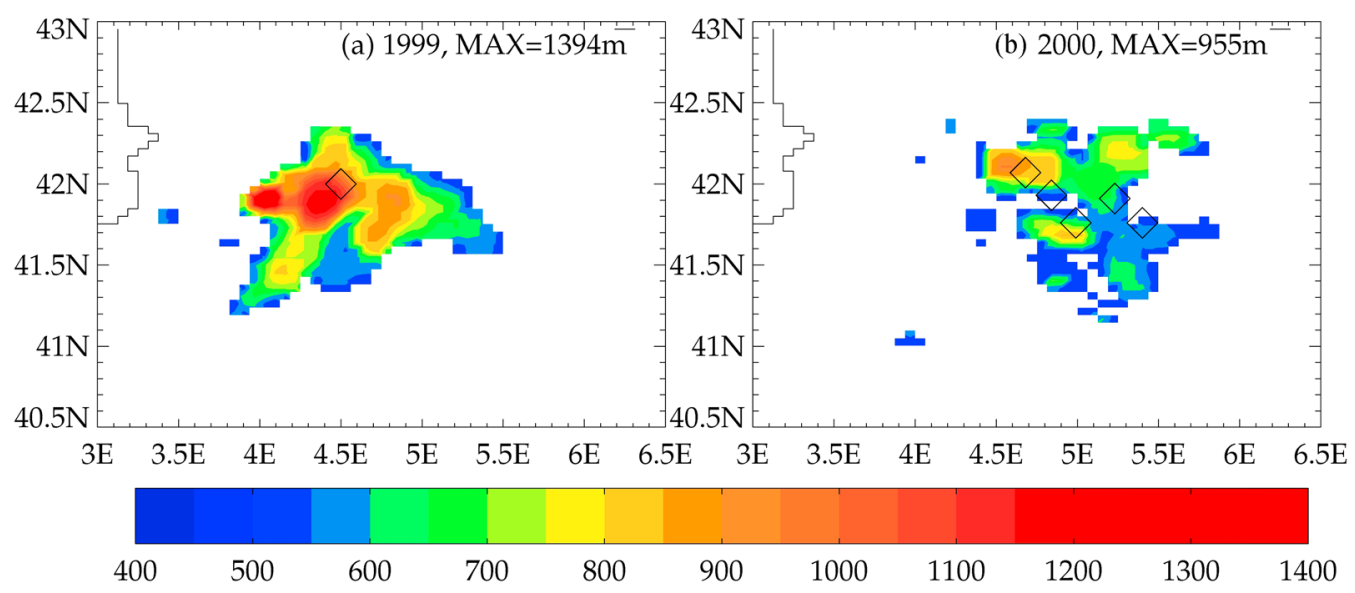

Figure 8. Maximum of the daily mixed layer depth (in meters) over (a) the winter 1999 and (b) the winter 2000 in the Gulf of Lion in MED16-ECMWF. The diamond in winter of 1999 corresponds to the cast $\mathrm{Y}$ of the MOOGLI3 campaign showing a homogeneous profile of temperature in January (cast done between the surface and $1000 \mathrm{~m}$ ). Diamonds in winter of 2000 correspond to homogeneous temperature profiles (between the surface and $650 \mathrm{~m}$ ) identified in the CORIOLIS database. Only depths greater than $D_{c}=500 \mathrm{~m}$ are plotted.

mulations (Figure 6). In winter, $D$ is generally deeper in MED16-ECMWF than in MED16-ERA40, except in some occasional intermediate convection events in the Levantine basin in 1999 and 2002. The winter average of this mixed layer maximum, hereafter $\bar{D}$, is consistent with this result (Table 3). The interannual variability in the Levantine basin indeed appears to be highly decreased in MED16-ERA40, where most of the deep reaching events observed in MED16ECMWF are absent (Figure 6a). A similar, though more pronounced and persistent, difference is observed in the Gulf of Lion. There MED16-ERA40 is unable to simulate any deep water formation during the simulated period (including the 11 year spinup) while MED16-ECMWF shows deep reaching convective events with large interannual variability (Figure 6d).

[32] As for the maximum winter mixed layer depth, the areas $A$ and consequently $\phi$, are larger in MED16-ECMWF than in MED16-ERA40 (except in 1999 and 2002 in the Levantine basin) and are smaller in the Gulf of Lion than in the eastern Mediterranean (Table 3). The correlation between the mean winter mixed layer depth maximum $\bar{D}$ and the winter horizontal extent $A$ is higher when there is only one persistent deep convective event during the winter lasting several weeks at the same place. For other cases, mesoscale convective eddies are randomly distributed in space during the winter, leading to a lower correlation (Table 3).

[33] In both simulations, the mean annual rate of deep water formation, $R$, shows large interannual variations over the 4 years of the simulation (Table 3). In MED16-ECMWF (resp. MED16-ERA40), in the Levantine basin, $R$ is in the range $0.05-0.40 \mathrm{~Sv}$ (resp. 0.06-0.12 Sv) and is much lower than the $0.9 \mathrm{~Sv}$ simulated by Lascaratos et al. [1993]. In the Aegean-Cretan Sea, $R$ is in the range $0.12-0.59 \mathrm{~Sv}$ (resp. $0.02-0.48 \mathrm{~Sv}$ ), consistent with the rate of $0.24 \mathrm{~Sv}$ found by Nittis et al. [2003] simulations. In the Adriatic Sea, $R$ is in the range 0.07-0.24 Sv (resp. 0.02-0.08 Sv), in agreement with the observational estimate of $0.36 \mathrm{~Sv}$ [Artegiani et al., 1997] or with the simulated rate of $0.30 \mathrm{~Sv}$ [Castellari et al., 2000; Mantziafou and Lascaratos, 2004]. In the Gulf of Lion,
$R$ is in the range $0.01-0.18 \mathrm{~Sv}$, which is relatively small compared with the formation rates reported in 1991-1992 [The THETIS Group, 1994] or with numerical estimates [Castellari et al., 2000]. Higher formation rates (1.3 Sv) were, however, simulated by MED16-ECMWF in the severe winter of 2005 [Béranger et al., 2009], in agreement with other observations [Schroeder et al., 2008]. As for the regional mixed layer depth maximum, $D$, and for the winter convection extent, $A, R$ is systematically larger in MED16-ECMWF than in MED16-ERA40, except in the Levantine basin in 1999 and 2002.

\section{Discussion}

\subsection{Impact of the Atmospheric Forcing} on the Convective Gyre in the Gulf of Lion

[34] Although both MED16-ECMWF and MED16-ERA40 reproduce the major ocean characteristics of the Mediterranean Sea, the convection in all the simulated winters is associated with a deeper mixed layer, longer convective events, formation of denser water masses, and higher rates of deep water formation in MED16-ECMWF than in MED16-ERA40, in better agreement with observations. In this section, we show that the better performance of MED16-ECMWF is to be related to the more intense winter atmospheric forcing (both wind stress and surface heat loss) (Figure 2) but also to the improved representation of the time-space characteristics of the forcing variability. The standard deviations of the net heat flux and the wind stress are indeed much larger in ECMWF than in ERA40, which can be attributed to a better representation of the mesoscale atmospheric disturbances (Figure 3). Comparing the surface wind simulated by ERA4O and ECMWF or retrieved from QuickSCAT scatterometer data with anemometer measurements collected by surface buoys at three different locations in the Mediterranean Sea (the Ligurian, Ionian, and Aegean basins), Ruti et al. [2008] indeed showed that the ECMWF and QuickSCAT winds are closer to the anemometer winds than the ERA40 winds, which are systematically too low. Pettenuzzo et al. [2010] also showed that winds 

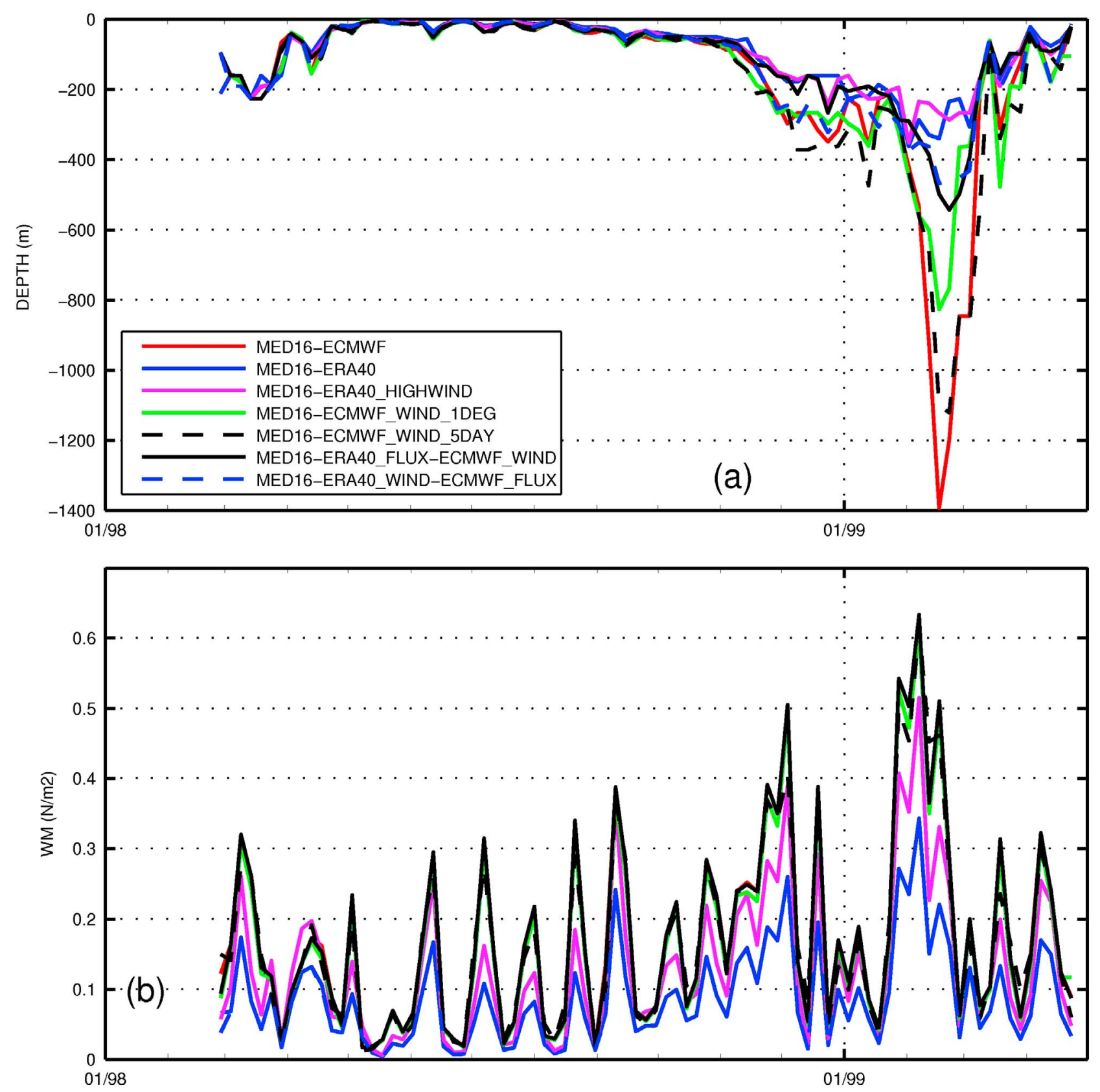

Figure 9. Five days averages of the regional maximum of (a) the mixed layer depth, $D$, (b) the wind stress modulus (in $\mathrm{N} \mathrm{m}^{-2}$ ), (c) the sea level height (in $\mathrm{cm}$ ), and (d) the barotropic stream function (in $\mathrm{Sv}, 1 \mathrm{~Sv}=10^{6} \mathrm{~m}^{3} \mathrm{~s}^{-1}$ ) during the period March 1998 to April 1999 for all the simulations: MED16-ECMWF (red), MED16-ERA40 (blue), MED16-ERA40_HIGHWIND (magenta), MED16-ECMWF_WIND_1DEG (green), MED16-ECMWF_WIND_5DAY (black dashed), MED16-ERA40_FLUX-ECMWF̄ WIND (black solid), MED16-ERA40 WIND-ECMWF_FLUX (blue dashed). All quantities are averaged over the Gulf of Lion $\left[41-43^{\circ} \mathrm{N}, 3.5-6 . \overline{5}^{\circ} \mathrm{E}\right]$.

are particularly underestimated in ERA40 compared with QuickSCAT winds near outflow regions of the major continental winds.

[35] The quasi absence of convection in the Gulf of Lion as found in the MED16-ERA40 experiment was already noted by Herrmann and Somot [2008]. Using a high-resolution embedded model of the Gulf of Lion and comparing a simulation forced by ERA40 with a simulation forced by finer resolution (equivalent horizontal resolution of $50 \mathrm{~km}$ ) forcing fields (the ARPEGE fields) obtained by a dynamical downscaling of ERA40, they showed that the latter, by providing larger ocean surface heat loss and wind intensity, were able to force realistic convection in this region. However, the particular sensitivity of the Gulf of Lion revealed by our two experiments compared with the other convective basins of the Mediterranean Sea suggests that a specific response to the 

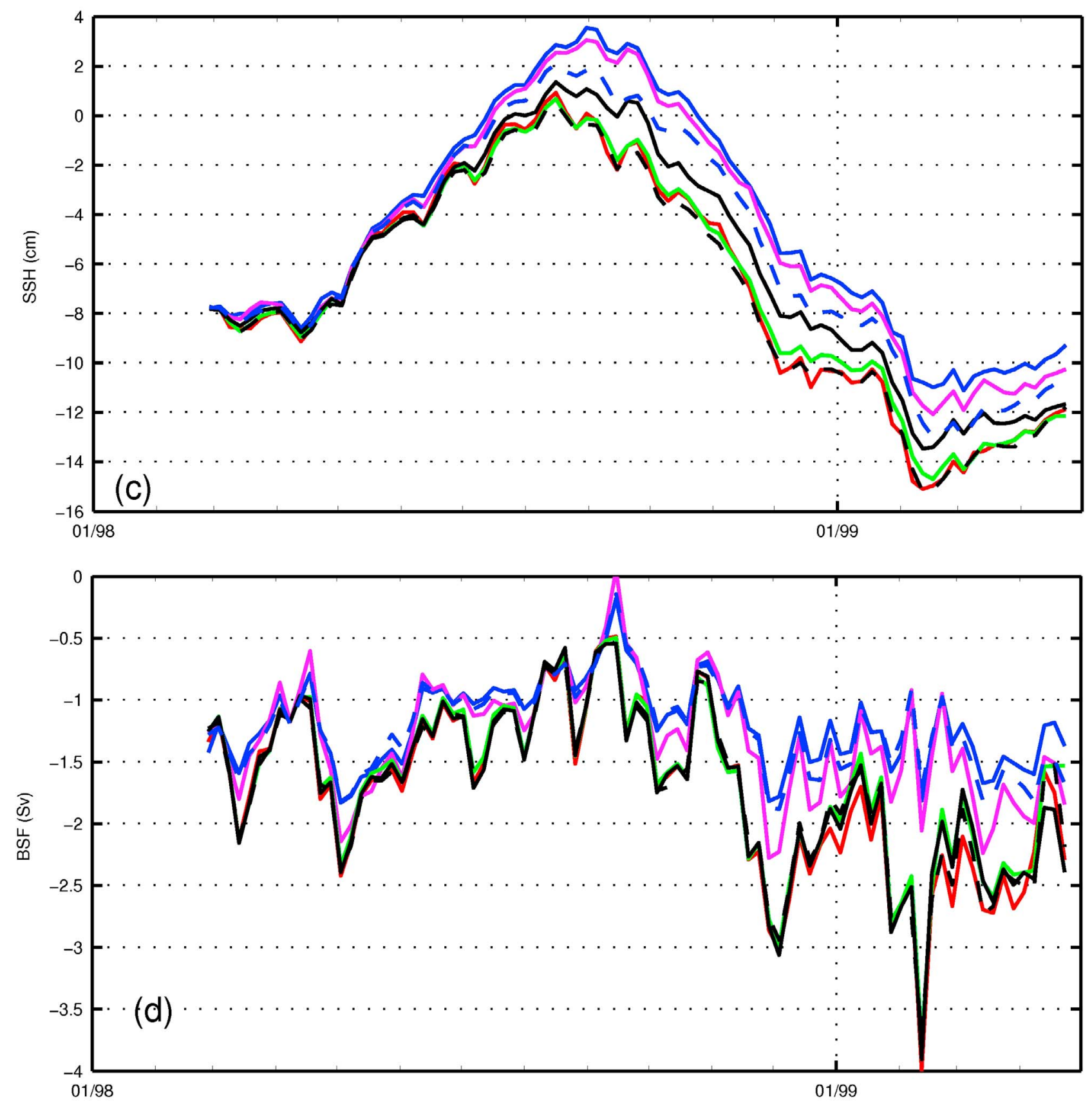

Figure 9. (continued)

atmospheric forcing is at work in this region. In particular, it is believed that the intensity of the wind and the magnitude of the heat loss are not the only ingredients responsible for the differences in the convection activity between the two experiments. We argue that the major impact of the higher resolution of the atmospheric model providing the $E C M W F$ product is to better reproduce the spatial pattern of the forcing through interaction of the atmospheric flow with the finescale land orography. More specifically, adequate channeling of the winds by the valleys and mountains appears to be a prerequisite to driving realistic steady patterns of the Mistral and Tramontane winds, which both control the gyre circulation and stratification in the convection area.

[36] To substantiate our conclusions, we chose to analyze in more detail a case study, the winter of 1998-1999, as it corresponds to the winter where deep convection is well reproduced in MED16-ECWMF. During this winter, the MED16-ECMWF and MED16-ERA40 experiments show contrasted evolution of the characteristics of the cyclonic gyre of the Gulf of Lion (Figure 9). During the fall, the gyre is present in all of both experiments (Figure 9d) and is related to the surface cyclonic circulation of the Mediterra- 
(a) MED16-ECMWF

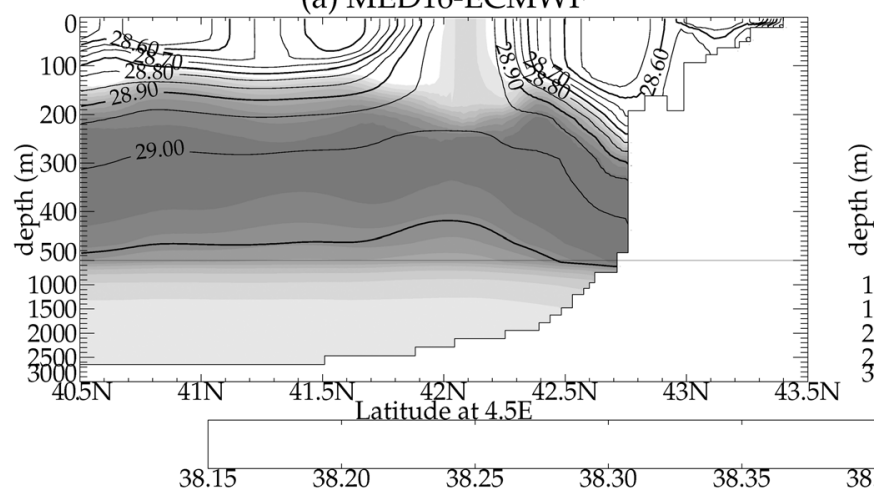

(b) MED16-ERA40

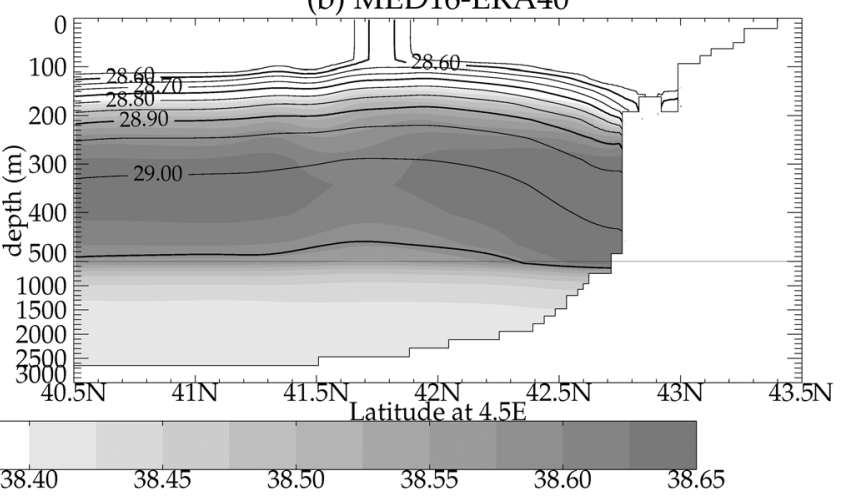

Figure 10. Vertical sections of salinity (in psu) (in gray) and potential density (in contours from 28.5 to 29.15 by 0.05 ) at $5^{\circ} \mathrm{E}$ from $40.5^{\circ} \mathrm{E}$ to $43.5^{\circ} \mathrm{E}$ on 18 December 1998 , in the Gulf of Lion in (a) MED16ECMWF and (b) MED16-ERA40.

nean Sea. The cyclonic circulation favors air-sea exchanges within the gyre by trapping the water masses, which are more efficiently exposed to surface buoyancy loss through air-sea fluxes. These fluxes tend to counteract the stabilizing effects of advection by the northern current or lateral eddy heat fluxes due to baroclinic instability [Madec et al., 1991; Jones and Marshall, 1993]. During November 1998 in MED16-ECMWF (resp. MED16-ERA40), the average transport of the cyclonic gyre was increased by $2.3 \mathrm{~Sv}$ (resp. 1 $\mathrm{Sv}$ ), reaching up to $3 \mathrm{~Sv}$ (resp. $1.8 \mathrm{~Sv}$ ) at the end of the month (Figure 9d), while the monthly averaged sea surface height shows a deepening of about $6 \mathrm{~cm}$ (resp. $4.4 \mathrm{~cm}$ ) (Figure 9c). At the beginning of December 1998, the cyclonic gyre was well present in MED16-ECMWF (Figure 10a), and the SSH dropped to a value of $-15 \mathrm{~cm}$ in the center of the gyre (Figure 11a). Subsequently, a first deepening of the mixed layer maximum $D$ down to about $300 \mathrm{~m}$ (Figures 9a, 10a and $11 \mathrm{~b}$ ) was observed 5 days after a wind gust (Figures 11a and 9b) in MED16-ECMWF, but in MED16-ERA40 (Figures 9a and $10 \mathrm{~b}$ ). This event was followed by a period of reduced variability in the mixed layer depth maximum $D$, which stayed at about $200 \mathrm{~m}$ due to a decrease of the wind and of the surface heat loss from mid-December 1998 to mid-January 1999 (Figure 9a). From the end of January to mid-February 1999, after several strong wind gusts associated with substantial ocean surface heat loss, deep convection was initiated and reached at about $1,400 \mathrm{~m}$ in mid-February (Figures 9a, $12 \mathrm{a}$ and $12 \mathrm{~b}$ ). During this period, the average transport of the cyclonic gyre was again increased by $2.3 \mathrm{~Sv}$ in MED16ECMWF, reaching $4 \mathrm{~Sv}$, while it only increased by $1 \mathrm{~Sv}$, reaching $2 \mathrm{~Sv}$, in MED16-ERA40 (Figure 9d). The SSH dropped by about $5 \mathrm{~cm}$ in MED16-ECMWF, reaching about $-20 \mathrm{~cm}$ in the center of the gyre (Figure 12a), and only by $3.8 \mathrm{~cm}$ in MED16-ERA40.

[37] To investigate the separate impact of changing the wind intensity from the effect of improved channeling by mountains, we ran several sensitivity experiments of 1 year duration for the winter of 1999, starting from the same initial conditions as the main MED16 experiments (see section 2.2). In these sensitivity experiments, the timespace characteristics of the forcing were varied. The results are compared with the MED16-ECMWF experiment considered as the reference experiment. Five sensitivity experi- ments were thus carried out in which the wind stress and/or the heat fluxes are modified according to the following protocol (Table 2):

[38] 1. MED16-ERA40_HIGHWIND: All forcing fields as in ERA40, except that the wind stress modulus is multiplied by a factor of 1.5 .

[39] 2. MED16-ERA40_WIND-ECMWF_FLUX: Wind stress as in $E R A 40$ and fluxes from $E C M W \bar{F}$.

[40] 3. MED16-ERA40_FLUX-ECMWF_WIND: Wind stress as in $E C M W F$ and fluxes from ERA40.

[41] 4. MED16-ECMWF_WIND_1DEG: All forcing fields as in $E C M W F$, except that the wind stress is smoothed spatially on a $1^{\circ} \times 1^{\circ}$ grid equivalent to that ERA40.

[42] 5. MED16-ECMWF_WIND_5DAY: All forcing fields as in $E C M W F$ except that the wind stress is low-pass filtered with a time window of 5 days.

[43] During the phase of intermediate convection in December 1998 (Figure 9a), all the sensitivity experiments show only small changes of the mixed layer depth maximum $D$. Those using the ERA40 fluxes with modified wind stress (MED16-ERA40_HIGHWIND and MED16-ERA40_FLUXECMWF_WIND) show a slightly increased deepening of the mixed layer by $50 \mathrm{~m}$ (mixed layer depth of $250 \mathrm{~m}$ ) compared with MED16-ERA40. Those using the ECMWF fluxes with modified wind stress show slightly shallower (by $50 \mathrm{~m}$ ) mixed layers (mixed layer depth of $300 \mathrm{~m}$ ) compared with MED16-ECMWF. In early December 1998, a surprisingly enhanced deepening ( $400 \mathrm{~m}$ instead of $300 \mathrm{~m})$ is noted in MED16-ECMWF_WIND_5DAY (Figures 9a and 11d), despite the fact that the wind intensity of the low-pass timefiltered wind stress is globally lower $\left(0.4 \mathrm{~N} \mathrm{~m}^{-2}\right.$ compared with $0.8 \mathrm{~N} \mathrm{~m}^{-2}$ in $E C M W F$ ) (Figure $9 \mathrm{~b}$ ). In that experiment, the wind stress maximum better coincides with the gyre center in $42^{\circ} \mathrm{N}-5^{\circ} \mathrm{E}$ (Figure 11c) than in MED16-ECMWF (Figure 11a). This is a consequence of the Mistral winds being rotated by $20^{\circ}$ in the clockwise direction compared with $E C M W F$. Additionally, the time smoothing generates a more stable wind stress, which shows a persistent pattern staying at the same position (not shown). This is because time filtering impedes high-frequency displacements of the wind maximum.

[44] The period of reduced variability in the mixed layer depth maximum $D$ which occurred between the strong wind 
(a) MED16-ECMWF

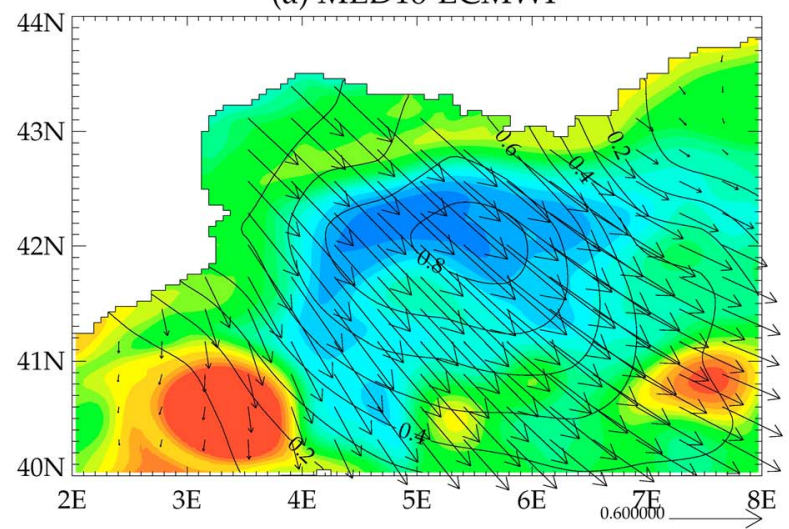

(c) MED16-ECMWF_WIND_5DAY

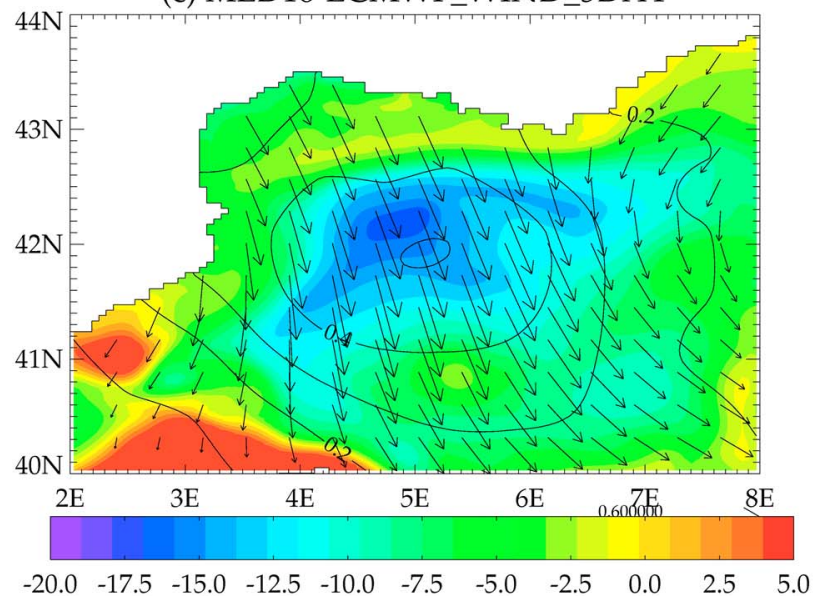

(b) MED16-ECMWF

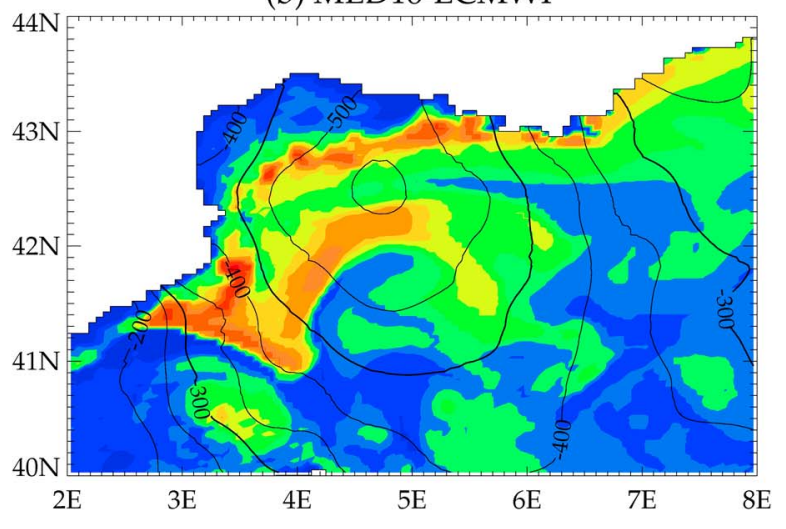

(d) MED16-ECMWF_WIND_5DAY

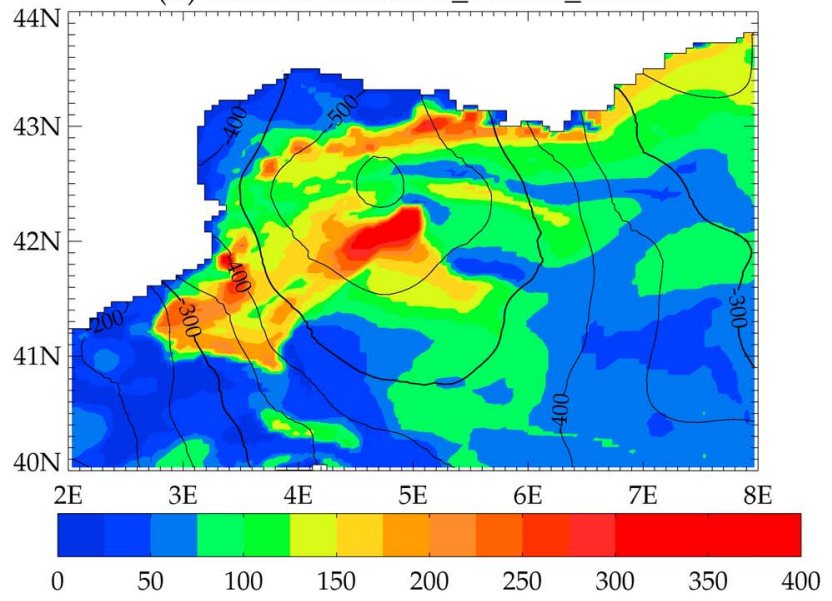

Figure 11. (left) Wind stress vectors and intensity (in $\mathrm{N} \mathrm{m}^{2}$ ) (in black contours from 0.4 to 1.2 every 0.1 superimposed on the sea surface height (in colors, in $\mathrm{cm}$ ) and (right) heat flux $Q$ (in black contours from -900 to 0 by $100 \mathrm{~W} \mathrm{~m}^{-2}$ ) on 5 December 1998 , and the mixed layer depth (in colors, in m) lagging by one week on 13 December 1998: ( $a$ and b) MED16-ECMWF, (c and d) MED16-ECMWF_WIND_5DAY.

events of December 1998 and February 1999 is present in all of the sensitivity experiments. The ocean mixed layer depth was quite shallow, reaching about $200 \mathrm{~m}$ in all the simulations at the end of January (Figure 9a). Consequently, one can consider that the five sensitivity experiments (Table 2) started from similar initial conditions prior to the deep convective event of February 1999. The MED16-ECMWF winds are the most intense (Figures 9b, 12a, 12c, 13a, and 13c). The maximum of the wind stress was located in a quasi steady cell which best coincides with the center of the cyclonic gyre associated with the deep convection area (Figure 12a). Thus a vigorous steady heat loss of about $600 \mathrm{~W} \mathrm{~m}^{-2}$ (Figures $12 \mathrm{~b}$, $13 \mathrm{~b}$, and 13d) associated with these strong, persistent winds over the convective region was able to destabilize the water column, mixing the fluid down to great depths (Figures 9a, $12 \mathrm{~b}, 13 \mathrm{~b}$, and 13d). Spatially smoothing the winds (MED16ECWMF_WIND_1DEG winds) essentially decreased the wind stress intensity (Figures 9b, 13a), reducing the convection depth to only $800 \mathrm{~m}$ (Figure 9a). The time filtering (MED16-ECMWF_WIND_5DAY winds), on the other hand, led to the formation of a relatively steady cell of winds (Figure 13c) well positioned above the deep water formation area as during the December event (Figure 11c) and to fairly deep $(1100 \mathrm{~m})$ convection (Figure $9 \mathrm{a})$.
[45] By contrast, in ERA40, even if the Mistral and the Tramontane flows are well reproduced, the direction of the wind is randomly shifted by $5^{\circ}-10^{\circ}$ compared with those in $E C M W F$, so that the ERA40 wind maximum was rarely positioned above the cyclonic gyre center. Besides, during the strong wind gust of February 1999, the winds in MED16ERA40 (not shown) and MED16-ERA40_HIGHWIND (Figure 12c) were organized along an elongated elliptic (instead of quasi circular) pattern covering the deep water formation area. Even when the intensity of the ERA40 winds was increased by a factor of 1.5 (Figures $9 \mathrm{~b}$ and $12 \mathrm{c}$ ), the mixed layer depth maximum $D$ only reached $320 \mathrm{~m}$ (Figure 9a). The deteriorated representation of the mixed layer deepening in sensitivity experiments $1-2$ (Table 2) forced by winds derived from ERA 40 highlights the crucial impact of the spatial distribution of the winds on the convection. The MED16-ERA40_FLUX-ECMWF_WIND confirms this conclusion, as it shows a drastic enhancement (by a factor 1.8) of the convection and a deeper SSH low in the center of the gyre with respect to MED16-ERA40, both effects being attributed to using $E C M W F$ winds instead of that ERA40.

[46] Sensitivity experiments 3, 4, and 5 (Table 2) confirm the major role of the spatial structure of the wind in control- 
(a) MED16-ECMWF

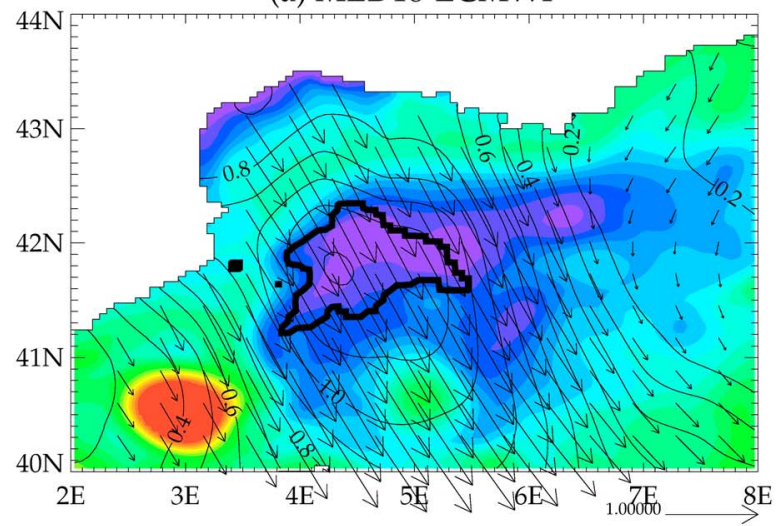

(c) MED16-ERA40_HIGHWIND

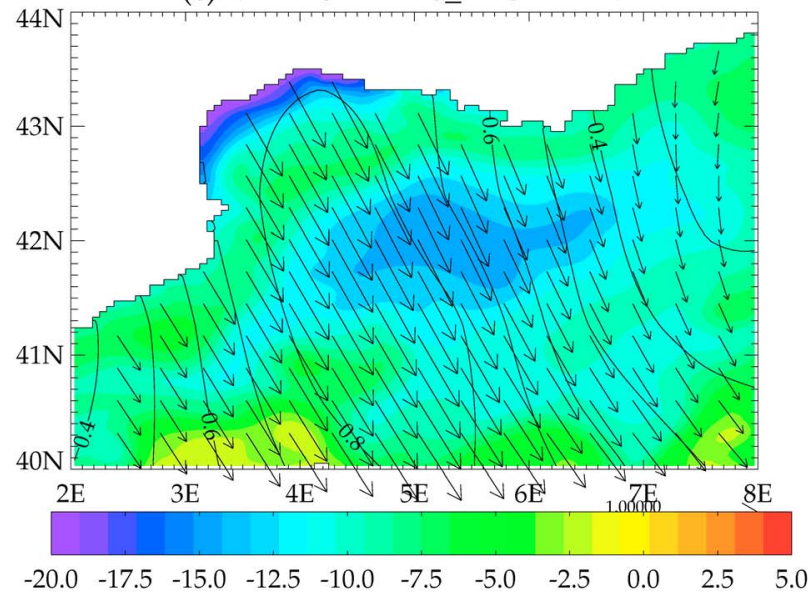

(b) MED16-ECMWF

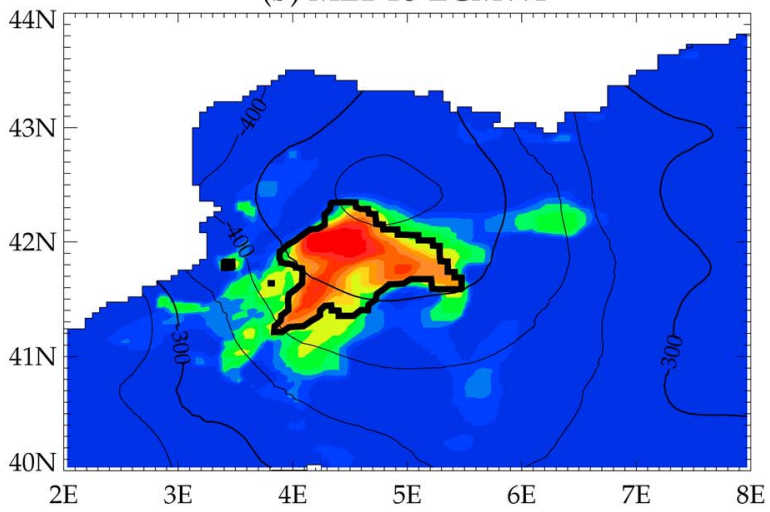

(d) MED16-ERA40_HIGHWIND

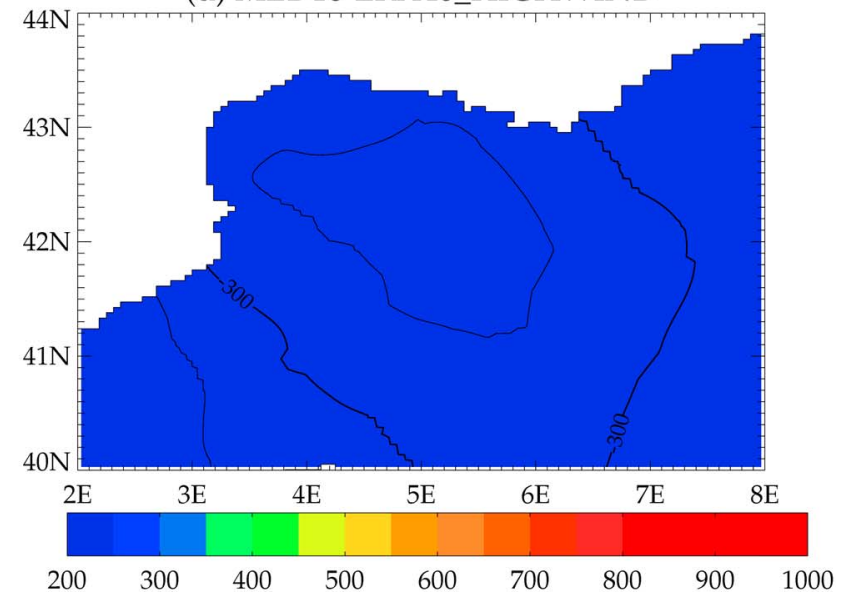

Figure 12. (left) Wind stress vectors and intensity (in $\mathrm{N} \mathrm{m}^{2}$ ) (in black contours from 0.4 to 1.2 every 0.1 superimposed on the sea surface height (in colours, in $\mathrm{cm}$ ) and (right) heat flux $Q$ (in black contours from -900 to 0 by $100 \mathrm{~W} \mathrm{~m}^{-2}$ ) on 11 February 1999 , and the mixed layer depth (in colours, in m) lagging by one week on 16 February 1998: (a and b) MED16-ECMWF, (c and d) MED16-ERA40 HIGHWIND. Also, shown as a heavy black line, is the envelope of the convective area in MED1 $\overline{6}$-ECMWF in winter 1999.

ling the convection in the Gulf of Lion. The improved spatial structure of the ECMWF surface winds is made possible by a better representation of the orography in the finer resolution ECMWF atmospheric model. Even experiments 4 and 5 (Table 2), which were forced by low-pass filtered (in time or in space) $E C M W F$ winds, still feel the land orography by construction. Enhanced spatial resolution of the model is thought to improve channeling of the winds by the mountains and to generate a path of maximum wind stress which better coincides with the cyclonic circulation and thus covers the deep-water formation region. This seems to be a prerequisite to an adequate representation of the convection, as experiments 3-5 indeed produced a much deeper convection compared with MED16-ERA40. This condition is often met in $E C M W F$, but not in ERA40. Additional ingredients to enhanced deep convection are, of course, the intensity of the wind and the pattern of the winter heat fluxes. The latter is indeed very different between ERA40 and ECMWF (Figures $12 \mathrm{~b}$ and $12 \mathrm{~d}$, for example), and this difference is most probably responsible for the shallower convection obtained in MED16-ERA40_ FLUX-ECMWF_WIND compared with
MED16-ECMWF, although both are forced with the same $E C M W F$ winds.

\subsection{Link Between the Convection and the SSH}

[47] In all simulations, there is a SSH drop associated with the mixed layer deepening (Figure 9c). For example in December 1998, the drop is, however, smaller $(4.5 \mathrm{~cm})$ in experiments 1 and 2 forced with the ERA40 winds (MED16ERA40_HIGHWIND, MED16-ERA40_WIND-ECMWF FLUX and MED16-ERA40) than in experiments 3-5 force $\overline{-}$ by the ECMWF winds (MED16-ECMWF WIND 1DEG, MED16-ECMWF_WIND_5DAY and MED16-ECMWF) $(6 \mathrm{~cm})$. The same conclusions hold for the mean barotropic stream function (Figure 9d). We think the wind stress impacts the mean $\mathrm{SSH}$ in the cyclonic convection gyre, as the $\mathrm{SSH}$ is a signature of the surface transport of that gyre. On the other hand, in the Gulf of Lion, we observe in some years significant spatial correlation between the mixed layer depth maximum $D$ and the isopleths of SSH (Table 4), especially during strong events like those occurring during the winter of 1999 or 2000 . As shown in Figures 12a, 12b, and 13 , the pattern of the mixed layer depth indeed coincides 
(a) MED16-ECMWF WIND 1DEG

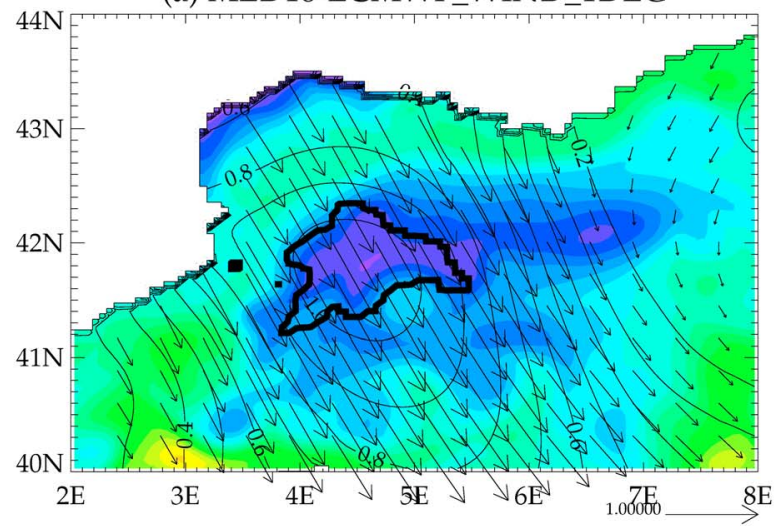

(c) MED16-ECMWF_WIND_5DAY

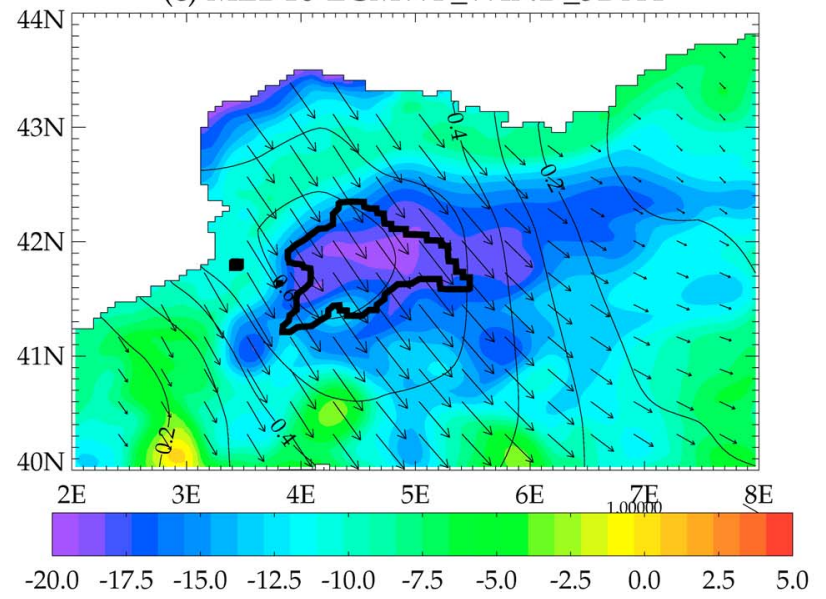

(b) MED16-ECMWF WIND 1DEG

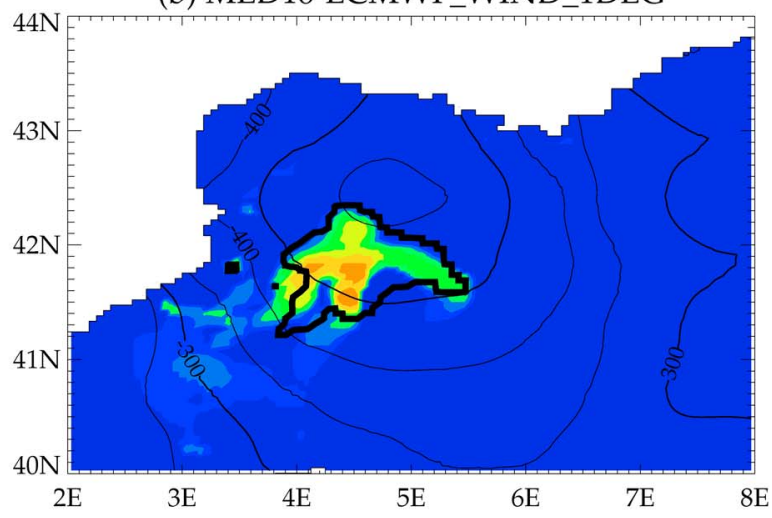

(d) MED16-ECMWF_WIND_5DAY

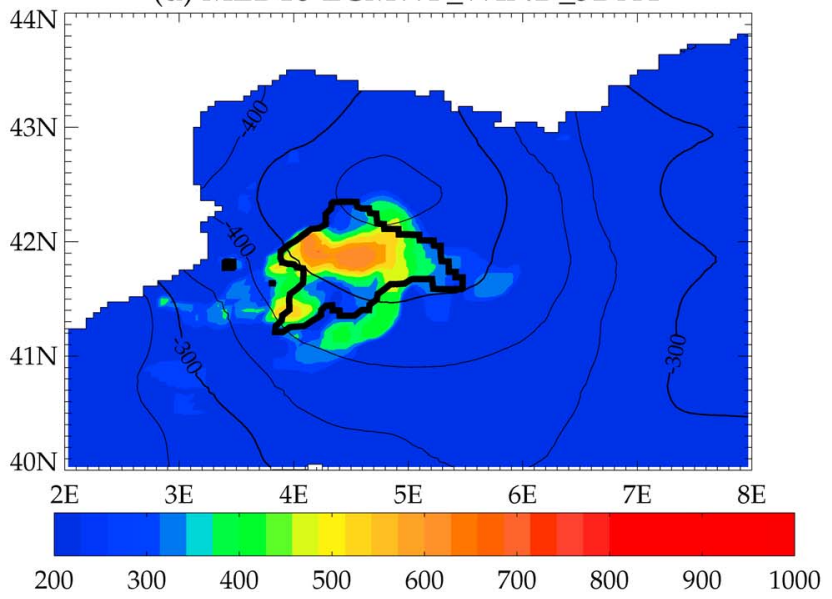

Figure 13. As in Figure 11, but (a and b) MED16-ECMWF_WIND_1DEG and (c and d) MED16ECMWF_WIND_5DAY.

well with the SSH pattern during the deep convection events, a conclusion already drawn by Herrmann et al. [2009]. The correlation indicates that in addition to wind stress, convection plays a significant role in driving the gyre circulation [Crépon et al., 1989] or, conversely, that the circulation plays a role in controlling the convection. By contrast, the spatial correlation between the mixed layer depth maximum $D$ and the barotropic stream function is not significant in particular in winter 1999 (Table 4), suggesting that enhancement of the convection is mainly controlled by the surface circulation. Furthermore, in MED16-ECMWF, the coincidence between the pattern of deep mixing efficiency (as diagnosed from the number of days during which a deep mixed layer is observed) and the pattern of SSH (Figure 14a) is better than the coincidence with the pattern of the maximum of the barotropic stream function (not shown).

[48] The relation between the SSH and the deep mixing efficiency is also found in the other convective basins, but the degree of correlation varies from one region to the other. In the Aegean-Cretan Sea, as in the Adriatic Sea, a weak relation between the large-scale cyclonic circulation and deep convection efficiency is noted in the two simulations (Figures 14b and 14c). In the Levantine basin, however, the area of deep reaching convection is centered in the cyclonic circulation characterized by a deep in the SSH in MED16-
ECMWF (Figure 14c). This agrees with the LIWEX observations [The LIWEX Group, 2003], showing deep convection in the Rhodes Gyre but also in random mesoscale eddies that are not related to any cyclonic gyre. The results are not so different between the two simulations, but the deep convection efficiency is higher in MED16-ECMWF than in MED16ERA40 (not shown). Moreover the SSH in the center of the Rhodes Gyre is deeper by about 2-3 cm in MED16-ECMWF than in MED16-ERA40 (not shown), which is the signature

Table 4. Spatial Correlation Coefficients Between the Sea Level Height (SSH) or the Barotropic Stream Function (BSF) and the Maxium Depth and Days of Deep Convection in the Gulf of Lion in MED16-ECMWF for Each Year of the Studied Period and the Averaged Period (1998-2002)

\begin{tabular}{llllll}
\hline Winter & 1999 & 2000 & 2001 & 2002 & $1998-2002$ \\
\hline BSF & 0.08 & 0.23 & 0.08 & 0.06 & 0.06 \\
SSH & 0.40 & 0.37 & 0.13 & 0.01 & 0.27 \\
& \multicolumn{5}{c}{ Number of Days ${ }^{\mathrm{b}}$} \\
BSF & 0.3 & 0.05 & 0.28 & 0.05 & 0.17 \\
SSH & 0.53 & 0.53 & 0.37 & 0.26 & 0.47 \\
\hline
\end{tabular}

${ }^{\mathrm{a}} D$, mixed layer depth maximum over the winter areas $A$.

${ }^{b}$ Number of days per winter for which the convection was deeper than $D_{c}$. 
(a)

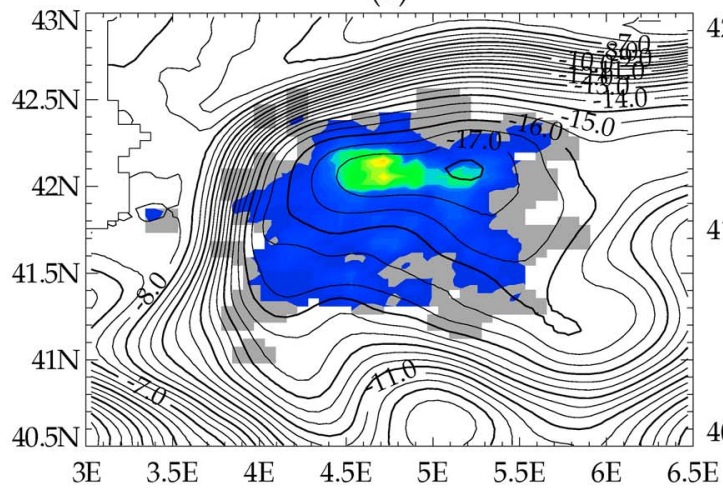

(b)

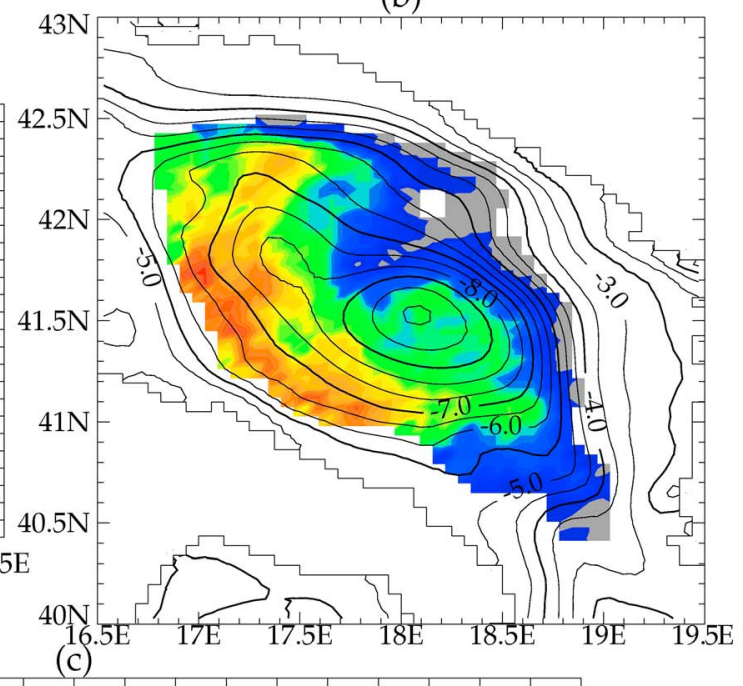

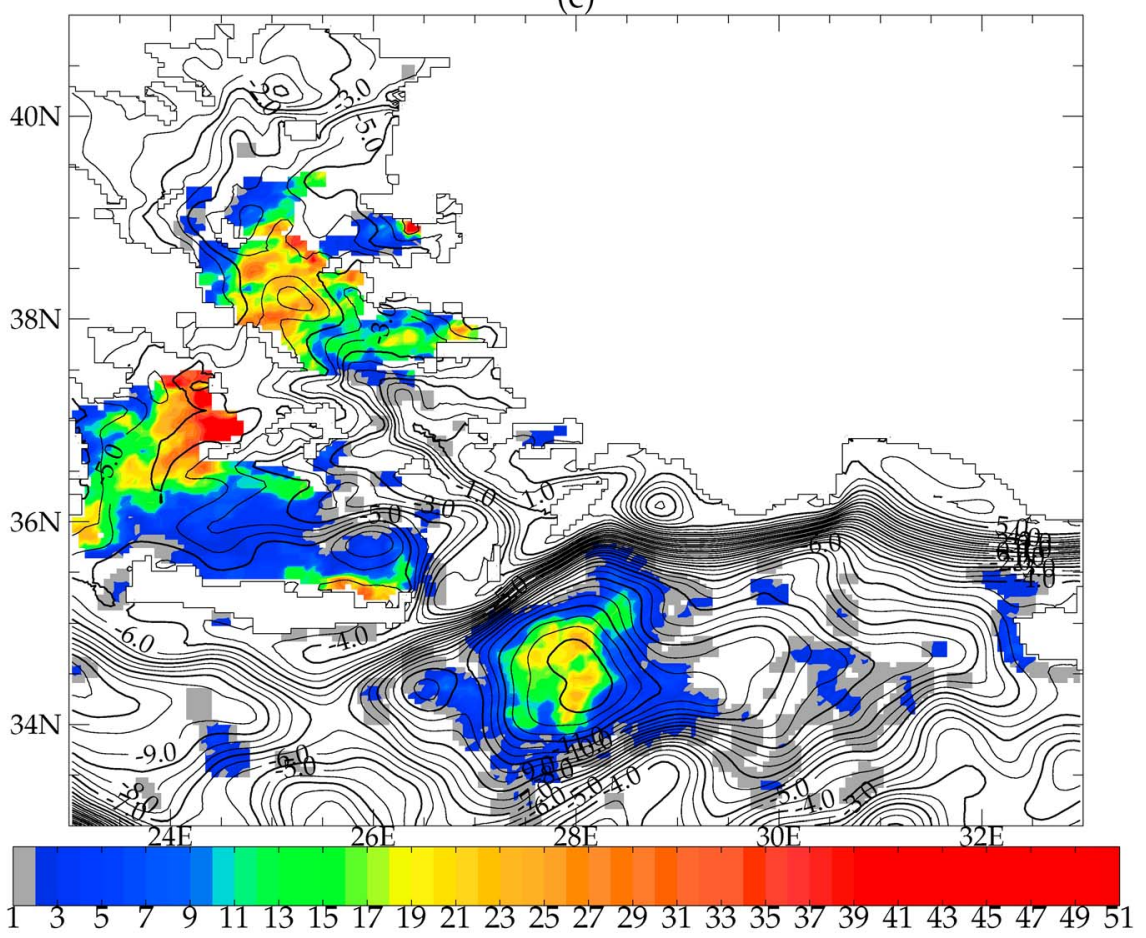

Figure 14. January-March averaged sea surface height (black contours every $0.5 \mathrm{~cm}$ ) superimposed on the mean number of days per year (filled colored contours) in which the mixed layer depth was higher than the critical value $D_{c}$ averaged over the 4 year simulation with MED16-ECMWF in (a) the Gulf of Lion, (b) the Adriatic Sea, and (c) the Aegean-Cretan Sea and Levantine basin.

of a more intense convection and consequently of a better defined gyre.

\section{Concluding Remarks}

[49] Deep water formation is an essential ingredient of the thermohaline circulation of the Mediterranean Sea. The present study demonstrates the crucial impact of the spatial distribution of the atmospheric forcing on the characteristics and occurrences of the winter convective mixing. The five sensitivity experiments investigating the effect of the wind intensity versus the effect of the orographic control of the wind on the convection strongly suggests that the channel- ing of the wind is the major process controlling the intensity of the convection in the Gulf of Lion. On the basis of these results of the 4 year experiment with $E C M W F$ forcing, only the Gulf of Lion, and to a lesser degree the Levantine basin, appear to respond to the atmospheric forcing via a welldeveloped preconditioning phase helping to remove buoyancy in a well-defined area. This is because the steady spatial structure of the wind stress in the Gulf of Lion occurs to a large extent as a response to the Mistral and Tramontane winds, which are mainly controlled by the orography of the Alps and the Massif Central, and the Massif Central and the Pyrénées, respectively. 
[50] In the Gulf of Lion and in the Levantine basin, the deepening of the mixed layer is correlated to a deepening of the SSH in the gyre center (Table 4), showing that there exists a baroclinic structure of the gyre forced by the deep formation process. This is in agreement with Herrmann et al. [2009]. However, the mechanisms behind this relationship need to be further investigated if one wants to monitor the variability of the convection through changes in the gyre dynamics. Our results show that this can be achieved via analyses of numerical simulation only if the latter are based on atmospheric forcing fields of sufficient resolution.

[51] It should be noted that the present analysis does not deal with the impact of changes in surface freshwater forcing on the response of the convective gyres. Through increased evaporation during winter and changes in the precipitation patterns, these are expected to create substantial modifications of the salinity (and therefore of the density) distribution in these gyres. The salinity distribution controls to some extent both the large-scale preconditioning of the gyres and the efficiency of the mixing phase, and may therefore explain part of the contrast between the responses of the different convection regions.

[52] The detailed comparison of our simulation results with available observations has highlighted the lack of relevant observations to assess the variability of the convection over recent decades. There is indeed a crucial need for long time series, in particular in the eastern Mediterranean and in the Gulf of Lion, which could be achieved in the context of the HyMex program (http://www.hymex.org). As far as coupled ocean atmosphere models are concerned, the present study shows that these models in the Mediterranean Sea should have an atmospheric grid size of $50 \mathrm{~km}$ at most [Sotillo et al., 2005; Somot et al., 2006], and probably less, to simulate the water mass formation in the Mediterranean Sea. This has to be considered if one wants to correctly estimate the impact of climate change on the Mediterranean hydrography and consequently on its thermohaline circulation.

\section{Notation}
AW Atlantic Water
LIW Levantine Intermediate Water
CIW Cretan Intermediate Water
LDW Levantine Deep Water
CDW Cretan Deep Water
NAdDW North Adriatic Deep Water
SAdDW Southern Adriatic Deep Water
ADW Adriatic Deep Water
EMDW Eastern Mediterranean Deep Water
WMDW Western Mediterranean Deep Water
MOW Mediterranean Outflow Water
TDW Tyrrhenian Deep Water
EMT Eastern Mediterranean Transient
ECMWF European Center of Medium-range Weather Forecast
ECMWF present ECMWF analysis (March 1998 to 2002), resolution of $\sim 60 \times 60 \mathrm{~km}^{2}$ up to $40 \times 40 \mathrm{~km}^{2}$
ERA40 second ECMWF reanalysis (1987-2002), resolu- tion of $\sim 100 \times 100 \mathrm{~km}^{2}$
$D$ Mixed layer depth maximum

$D_{c}$ Critical value of D equal to $500 \mathrm{~m}$ in the western Mediterranean and $300 \mathrm{~m}$ in the eastern Mediterranean

$A$ Winter convection area, defined as the envelope of the daily areas calculated for each winter (January to March) in which the daily mixed layer is deeper than the critical depth $D_{c}$

$A^{T}$ Union extent of the winter convection area defined as the envelope of the four winter areas $A$

$\bar{D}$ Average of $D$ on $A$

$S$ salinity

$\theta$ : potential temperature $\left({ }^{\circ} \mathrm{C}\right)$

$\sigma_{\theta}$ potential density

$R$ rate of deep water formation

$\phi$ diameter of a circle whose surface is equal to $A$

$\phi^{T}$ diameter of a circle whose surface is equal to $A^{T}$ SSH Sea Surface Height

$B S F$ Barotropic Stream Function

$Q$ Heat flux (defined in section 2.2)

[53] Acknowledgments. This work was supported by the French Mercator project (www.mercator-ocean.fr) and by the Service Hydrographique et Océanographique de la Marine (SHOM). Atmospheric forcing data sets were made available by the European Centre for Medium-range Weather Forecasts. This work was granted access to the HPC resources of IDRIS (Institut du Développement et des Ressources en Informatique Scientifique) of the Centre National de la Recherche Scientifique (CNRS) under allocation 2008 (i2008010227) made by Grand Equipement National de Calcul Intensif (GENCI). The Coriolis data were collected and made freely available by the Coriolis project and programmes that contribute to it (http://www.coriolis.eu.org).

\section{References}

Alhammoud, B., K. Béranger, L. Mortier, and M. Crépon (2005), Surface circulation of the Levantine Basin: Comparison of model results with observations, Prog. Oceanogr., 66(2-4), 299-320, doi:10.1016/j. pocean.2004.07.015.

Artale, V., D. Iudicone, R. Santoleri, V. Rupolo, S. Marullo, and F. D’Ortenzio (2002), Role of surface fluxes in ocean general circulation models using satellite sea surface temperature: Validation of and sensitivity to the forcing frequency of the Mediterranean circulation, J. Geophys. Res., 107(C8), 3120, doi:10.1029/2000JC000452.

Artegiani, A., D. Bregant, E. Paschini, N. Pinardi, F. Raicich, and A. Russo (1997), The Adriatic Sea General Circulation. Part I: Air-sea interactions and water mass structure, J. Phys. Oceanogr., 27(8), 1492-1514, doi:10.1175/1520-0485(1997)027<1492:TASGCP>2.0.CO;2.

Astraldi, M., and G.-P. Gasparini (1992), The seasonal characteristics of the circulation in the North Mediterranean Basin and their relationship with the atmospheric-climatic conditions, J. Geophys. Res., 97, 95319540, doi:10.1029/92JC00114.

Astraldi, M., S. Balopoulos, J. Candela, J. Font, M. Gacic, G.-P. Gasparini, B. Manca, A. Theocharis, and J. Tintoré (1999), The role of straits and channels in understanding the characteristics of Mediterranean circulation, Prog. Oceanogr., 44, 65-108, doi:10.1016/S0079-6611(99)00021-X.

Bahurel, P., P. De Mey, C. Le Provost, and P.-Y. Le Traon (2002), Mercator project - GODAE Prototype system with applications. Example of the Mercator system. European Geophysical Society XXVII General Assembly, Nice, France, April.

Barnier, B. (1998), Forcing the ocean, in Ocean Modeling and Parameterization, NATO Sci. Ser., Ser. C, vol. 516, edited by E. P. Chassignet and J. Verron, pp. 45-80, Kluwer Acad., Amsterdam.

Béranger, K., L. Mortier, G.-P. Gasparini, L. Gervasio, M. Astraldi, and M. Crépon (2004), The dynamics of the Sicily Strait: A comprehensive study from observations and models, Deep Sea Res., Part II, 51, 411-440, doi:10.1016/j.dsr2.2003.08.004.

Béranger, K., L. Mortier, and M. Crépon (2005), Seasonal variability of water transports through the Straits of Gibraltar, Sicily and Corsica, derived from a high resolution model of the Mediterranean circulation, Prog. Oceanogr., 66(2-4), 341-364, doi:10.1016/j.pocean.2004.07.013.

Béranger, K., P. Testor, and M. Crépon (2009), Modelling water mass formation in the Gulf of Lion (Mediterranean Sea), in Dynamics of Mediterranean Deep Waters, CIESM Workshop Monogr., vol. 38, edited by F. Briand, pp. 91-100, Mediterr. Sci. Comm., Monaco. 
Blanke, B., and P. Delecluse (1993), Variability of the tropical Atlantic Ocean simulated by a general circulation model with two different mixed layer physics, J. Phys. Oceanogr., 23, 1363-1388, doi:10.1175/15200485(1993)023<1363:VOTTAO $>2.0 . \mathrm{CO} ; 2$.

Book, J. W., H. T. Perkins, L. Cavaleri, J. D. Doyle, and J. D. Pullen (2005), ADCP observations of the western Adriatic slope current during winter of 2001, Prog. Oceanogr., 66(2-4), 270-286, doi:10.1016/j. pocean.2004.07.014

Bozec, A., P. Bouruet-Aubertot, K. Béranger, and M. Crépon (2006), Mediterranean oceanic response under interannual high resolution atmospheric forcing: A focus on the Aegean Sea, J. Geophys. Res., 111, C11013, doi:10.1029/2005JC003427.

Brankart, J.-M., and P. Brasseur (1998), The general circulation in the Mediterranean Sea: A climatological approach, J. Mar. Syst., 18, 4170, doi:10.1016/S0924-7963(98)00005-0

Cardin, V., and M. Gacic (2003), Long-term heat flux variability and winter convection in the Adriatic Sea, J. Geophys. Res., 108(C9), 8103 doi:10.1029/2002JC001645.

Castellari, S., N. Pinardi, and K. Leaman (2000), Simulation of water mass formation processes in the Mediterranean Sea: Influence of the time frequency of the atmospheric forcing, J. Geophys. Res., 105(C10), 24,15724,181, doi:10.1029/2000JC900055.

Crépon, M., M. Boukthir, B. Barnier, and F. Aikman III (1989), Horizonta ocean circulation forced by deep-water formation. part I: An analytical study, J. Phys. Oceanogr., 19, 1781-1793, doi:10.1175/1520-0485 (1989)019<1781:HOCFBD>2.0.CO;2.

D’Ortenzio, F., D. Iudicone, C. Boyer Montegut, P. Testor, D. Antoine, S. Marullo, R. Santoreli, and G. Madec (2005), Seasonal variability of the Mixed layer depth in the Mediterranean Sea as derived from in-situ profiles, Geophys. Res. Lett., 32, L12605, doi:10.1029/2005GL022463.

Drillet, Y., R. Bourdallé-Badie, L. Siefridt, and C. LeProvost (2005), The Meddies in the Mercator North Atlantic and Mediterranean Sea eddyresolving model, J. Geophys. Res., 110, C03016, doi:10.1029/ 2003JC002170.

Fuda, J.-L., G. Etiope, C. Millot, P. Favali, M. Calcara, G. Smirglio, and E. Boschi (2002), Warming, salting and origin of the Tyrrhenian Deep Water, Geophys. Res. Lett., 29(19), 1898, doi:10.1029/2001GL014072.

Gascard, J.-C. (1978), Mediterranean deep water formation, baroclinic instability and oceanic eddies, Oceanol. Acta, 1(3), 315-330.

Gascard, J.-C., and C. Richez (1985), Water masses and circulation in the Western Alboran Sea and in the Straits of Gibraltar, Prog. Oceanogr., 15(3), 157-216, doi:10.1016/0079-6611(85)90031-X.

Herrmann, M., and S. Somot (2008), Relevance of ERA40 dynamical downscaling for modeling deep convection in the Mediterranean Sea, Geophys. Res. Lett., 35, L04607, doi:10.1029/2007GL032442.

Herrmann, M., J. Bouffard, and K. Béranger (2009), Monitoring openocean deep convection from space, Geophys. Res. Lett., 36, L03606, doi:10.1029/2008GL036422.

Jones, H., and J. Marshall (1993), Convection with rotation in a neutral Ocean: A study of open ocean deep convection, J. Phys. Oceanogr., 23, 1009-1039, doi:10.1175/1520-0485(1993)023<1009:CWRIAN $>2.0$ $\mathrm{CO} ; 2$.

Josey, S. (2003), Changes in the heat and freshwater forcing of the Eastern Mediterranean and their influence on deep water formation, J. Geophys Res., 108(C7), 3237, doi:10.1029/2003JC001778.

Killworth, P. D. (1976), The mixing and spreading phases of MEDOC I, Prog. Oceanogr., 7, 59-90, doi:10.1016/0079-6611(76)90005-7.

Klein, B., W. Roether, G. Civitarese, M. Gacic, B. Manca, and M. Ribera d'Alcala (2000), Is the Adriatic returning to dominate the production of Eastern Mediterranean Deep Water? J. Geophys. Res., 27(20), 3377-3380.

Lascaratos, A., and K. Nittis (1998), A high resolution three-dimensional numerical study of intermediate water formation in the Levantine Sea, J. Geophys. Res., 103(C9), 18,497-18,511, doi:10.1029/98JC01196.

Lascaratos, A., R. G. Williams, and E. Tragou (1993), A mixed layer study of the formation of Levantine Intermediate water, J. Geophys. Res., 98 14,739-14,749, doi:10.1029/93JC00912.

LIWEX Group (2003), The Levantine Intermediate Water Experiment (LIWEX) Group: Levantine basin: A laboratory for multiple water mass formation processes, J. Geophys. Res., 108(C9), 8101, doi:10.1029/ 2002JC001643.

Lopez-Jurado, J.-L., C. Gonzales-Pola, and P. Vélez-Belchi (2005), Observation of an abrupt disruption of the long-term warming trend at the Balearic Sea, western Mediterranean Sea, in summer 2005, Geophys. Res. Lett., 32, L24606, doi:10.1029/2005GL024430.

Madec, G., M. Chartier, P. Delecluse, and M. Crépon (1991), A three dimensional numerical study of deep-water formation in the northwestern Mediterranean Sea, J. Phys. Oceanogr., 21, 1349-1371, doi:10.1175/ 1520-0485(1991)021<1349:ATDNSO>2.0.CO;2.
Madec, G., F. Lott, P. Delecluse, and M. Crépon (1996), Large-scale preconditioning of deep-water formation in the northwestern Mediterranean Sea, J. Phys. Oceanogr., 26, 1393-1408, doi:10.1175/1520-0485(1996) 026<1393:LSPODW>2.0.CO;2.

Madec, G., P. Delecluse, M. Imbard, and C. Levy (1997), OPA, release 8, Ocean General Circulation reference manual, Technical report 96/xx, LODYC/IPSL, France, February.

Manca, B., V. Kovacevic, M. Gacic, and D. Viezzoli (2002), Dense water formation in the Southern Adriatic Sea and spreading into the Ionian Sea in the period 1997-1999, J. Mar. Syst., 33-34, 133-154, doi:10.1016/ S0924-7963(02)00056-8

Manca, B., G. Budillon, P. Scarazzato, and L. Ursella (2003), Evolution of dynamics in the eastern Mediterranean affecting water mass structures and properties in the Ionian and Adriatic Seas, J. Geophys. Res., 108(C9), 8102, doi:10.1029/2002JC001664.

Manca, B., V. Ibello, M. Pacciaroni, P. Scarazzato, and A. Giogetti (2006), Ventilation of deep waters in the Adriatic and Ionian Seas following changes in thermohaline circulation of the Eastern Mediterranean, Clim. Res., 31, 239-256, doi:10.3354/cr031239.

Mantziafou, A., and A. Lascaratos (2004), An eddy resolving numerical study of the general circulation and deep-water formation in the Adriatic sea, Deep Sea Res., Part I, 51(7), 921-952, doi:10.1016/j.dsr.2004.03.006.

Mariotti, A., M. W. Struglia, N. Zeng, and K.-M. Lau (2002), The hydrological cycle in the Mediterranean region and implications for the water budget of the Mediterranean Sea, J. Clim., 15, 1674-1690, doi:10.1175/ 1520-0442(2002)015<1674:THCITM $>2.0$. CO;2

Marshall, J., and F. Schott (1999), Open ocean deep convection: Observations, models and theory, Rev. Geophys., 37, 1-64, doi:10.1029/ 98RG02739.

MEDOC Group (1970), Observations of formation of deep water in the Mediterranean Sea, 1969, Nature, 227, 1037-1040, doi:10.1038/ $2271037 \mathrm{a} 0$.

Mertens, C., and F. Schott (1998), Interannual variability of deep water formation in the North Western Mediterranean, J. Phys. Oceanogr., 28 1410-1424, doi:10.1175/1520-0485(1998)028<1410:IVODWF $>2.0$. $\mathrm{CO} ; 2$.

Millot, C. (1999), Circulation in the western Mediterranean Sea, J. Mar. Syst., 20, 423-442, doi:10.1016/S0924-7963(98)00078-5.

Nittis, K., and A. Lascaratos (1998), Diagnostic and prognostic numerical studies of LIW formation, J. Mar. Syst., 18, 179-195, doi:10.1016/ S0924-7963(98)00011-6.

Nittis, K., A. Lascaratos, and A. Theocharis (2003), Dense water formation in the Aegean Sea: Numerical simulations during the Eastern Mediterranean Transient, J. Geophys. Res., 108(C9), 8120, doi:10.1029/ 2002JC001352.

Petrenko, A., Y. Leredde, and P. Marsaleix (2005), Circulation in a stratified and wind-forced Gulf of Lion, NW Mediterranean Sea: In situ and modeling data, Cont. Shelf Res., 25, 7-27, doi:10.1016/j.csr.2004.09.004.

Pettenuzzo, D., W. G. Large, and N. Pinardi (2010), On the corrections of ERA-40 surface flux products consistent with the Mediterranean heat and water budgets and the connection between basin surface total heat flux and NAO, J. Geophys. Res., 115, C06022, doi:10.1029/2009JC005631.

Reynaud, T., P. LeGrand, H. Mercier, and B. Barnier (1998), A new analysis of hydrographic data in the Atlantic and its application to an inverse modelling study, Int. WOCE Newsl., 32, 29-31.

Reynolds, R. W. (1988), A real-time global sea surface temperature analysis, J. Clim., 1, 75-87, doi:10.1175/1520-0442(1988)001<0075 ARTGSS $>2.0 . \mathrm{CO} ; 2$.

Robinson, A. R., et al. (1992), General circulation of the Eastern Mediterranean, Earth Sci. Rev., 32, 285-309, doi:10.1016/0012-8252(92)90002-B.

Roether, W., B. Manca, B. Klein, D. Bregant, D. Georgopoulos, V. Beitzel, V. Kovacevic, and A. Luchetta (1996), Recent changes in the eastern Mediterranean deep waters, Science, 271,333-335, doi:10.1126 science.271.5247.333

Ruti, P., S. Marullo, F. D’Ortenzio, and M. Tremant (2008), Comparison of analyzed and measured wind speeds in the perspective of oceanic simulations over the Mediterranean basin: Analyses, Quick-scat and buoy data, J. Mar. Syst., 70(1-2), 33-48, doi:10.1016/j.jmarsys.2007.02.026.

Schott, F., and K. Leaman (1991), Observations with Moored Acoustic Doppler Current Profilers in the convection Regime in the Gulf of Lion, J. Phys. Oceanogr., 21, 558-574, doi:10.1175/1520-0485(1991) $021<0558$ :OWMADC $>2.0 . \mathrm{CO} ; 2$.

Schroeder, K., G.-P. Gasparini, M. Tangherlini, and M. Astraldi (2006), Deep and intermediate water in the western Mediterranean under the influence of the Eastern Mediterranean Transient, Geophys. Res. Lett. 33, L21607, doi:10.1029/2006GL027121.

Schroeder, K., A. Ribotti, M. Borghini, R. Sorgente, A. Perilli, and G.-P. Gasparini (2008), An extensive western Mediterranean renewal between 
2004 and 2006, Geophys. Res. Lett., 35, L18605, doi:10.1029 2008 GL035146.

Somot, S., F. Sevault, and M. Déqué (2006), Transient climate change scenario simulation of the Mediterranean Sea for the 21st century using a highresolution circulation model, Clim. Dyn., 27, 851-879, doi:10.1007/s00382006-0167-z.

Sotillo, M. G., A. W. Ratsimandresy, J. C. Carretero, A. Bentamy, F. Valero, and F. Gonzalez-Rouco (2005), A high resolution 44-year atmospheric hindcast for the Mediterranean Basin: Contribution to the regional improvement of global reanalysis, Clim. Dyn., 25, 219-236, doi:10.1007/ s00382-005-0030-7.

Sur, H. L., E. Özsoy, and U. Ünlüata (1992), Simultaneous deep and intermediate depth convection in the northern Levantine Sea, winter 1992 , Oceanol. Acta, 16, 33-43.

Swallow, J. C., and G. F. Gaston (1973), The preconditioning phase of MEDOC 1969-I, Deep Sea Res., 20, 429-448.

Taillandier, V., A. Griffa, P.-M. Poulain, and K. Béranger (2006), Assimilation of Argo float positions in a Mediterranean circulation model, Geophys. Res. Lett., 33, L11604, doi:10.1029/2005GL025552.

Testor, P., K. Béranger, and L. Mortier (2005a), Modeling the deep eddy field in the southwestern Mediterranean: The life cycle of Sardinian Eddies, Geophys. Res. Lett., 32(13), L13602, doi:10.1029/2004GL022283.

Testor, P., U. Send, J.-C. Gascard, C. Millot, I. Taupier-Letage, and K. Béranger (2005b), The mean circulation of the southwestern Mediterranean Sea: The Algerian Gyres, J. Geophys. Res., 110, C11017, doi:10.1029/2004JC002861.

Theocharis, A., E. Balopoulos, S. Kioroglou, H. Kontoyiannis, and A. Iona (1999), A synthesis of the circulation and hydrography of the South
Aegean Sea and the Straits of the Cretan Arc (March 1994-January 1995), Prog. Oceanogr., 44, 469-509, doi:10.1016/S0079-6611(99) 00041-5.

Theocharis, A., B. Klein, K. Nittis, and W. Roether (2002), Evolution and status of the Eastern Mediterranean Transient (1997-1999), J. Mar. Syst., 33-34, 91-116, doi:10.1016/S0924-7963(02)00054-4.

THETIS Group (1994), Open-ocean deep convection explored in the Mediterranean, Eos Trans. AGU, 75(19), 217-221, doi:10.1029/94EO00893. Uppala, S. M., et al. (2005), The ERA-40 re-analysis, Q. J. R. Meteorol. Soc., 131, 2961-3012, doi:10.1256/qj.04.176.

$\mathrm{Wu}, \mathrm{P} ., \mathrm{K}$. Haines, and N. Pinardi (2000), Toward and understanding of deep-water renewal in the Eastern Mediterranean, J. Phys. Oceanogr., 30, 443-458, doi:10.1175/1520-0485(2000)030<0443:TAUODW $>2.0$. $\mathrm{CO} ; 2$

B. Alhammoud, P. Bouruet-Aubertot, A. Bozec, M. Crépon, M.-N Houssais, and P. Testor, LOCEAN, Université Pierre et Marie Curie, Tour 45-55, 4 Place Jussieu, F-75252 Paris CEDEX 05, France.

K. Béranger and L. Mortier, Department of Mechanical Engineering (UME), ENSTA-ParisTech, Chemin de la Hunière, F-91761 Palaiseau, France.

R. Bourdallé-Badie, CERFACS, 42 Ave. Gaspard Coriolis, F-31057 Toulouse CEDEX, France.

Y. Drillet, Mercator Ocean, 8-10 Rue Hermès, Parc Technologique du Canal, F-31520 Ramonville-Saint-Agne, France. 